\title{
OBSERVAÇõES PRELIMINARES SÔBRE A FAUNA BENTICA DE SEDIMENTOS MOLES DA BAIA DE SANTOS E REGIÕES VIZINHAS
}

\author{
(Recebido em 21/3/1967)
}

Luiz Roberto Tommasi

Instituto Oceanográfico da Universidade de São Paulo

\begin{abstract}
SYNOPSIS
The purpose of this paper is to give a preliminary qualitative assessment of the soft bottom macrofauna of the Bay of Santos and adjacent areas. Sixty-three samples were taken by the 'Emilia' with grab and otter trawl gears. 149 different species of benthic animals were collected, of which 52 were polychaets, 26 lamellibranchs, 20 echinoderms, 17 crustaceans, 14 gastropods, 4 cnidarians and 16 belonging to other taxonomic categories. The most frequent species were the polychaets Audouinia tentaculata, Poecilochaetus australis, Onuphis quadricuspis, Owenia fusiformis, Telepus setosus and Telepsavus costarum. The gastropod Littoridina australis var. nana occurred in high densities in the samples collected in the inner part of the Santos channel. Ophiactis lymani was found to be the most widely distributed ophiuran in this region. The lamellibranchs Mesodesma mactroides, Tivela mactroides, Donax hanleyanus and the thalassinid Callianassa major are common in the sand beaches of the bay. In the mangrove region numerous decapods occurred of the following genera: Uca, Ucides, Aratus, Metasesarma, the "Maria mulata", crab Goniopsis cruentata, etc.

Five different station groups and two more areas may be recognized in the
\end{abstract} region of the Bay of Santos and the homonimous channel.

\section{INTRODUÇÃO}

Como há uma crescente poluição na baía de Santos e regiōes vizinhas, e à vista da possível alteração drástica das condições biológicas decorrentes da planejada abertura de um canal de acesso à Companhia Siderúrgica Paulista (COSIPA), que poderá vir a modificar as condições atualmente reinantes, resolvemos divulgar os dados que possuimos sôbre os grupos bênticos que coletamos nessa região durante a realização do nosso projeto de coletas dos equinodermas brasileiros, com especial atenção ao litoral paulista. Embora êsses dados sejam preliminares, contribuem para o levantamento faunístico e distribuição das espécies dos fundos moles da baía de Santos e regiôes vizinhas. Outro aspecto que nos pareceu importante para divulgar êsses achados, é a recomendação do Seminário sôbre a História Natural dos Organismos Aquáticos do Brasil (Vanzolini, 1964) sôbre a realização do levantamento faunístico e mapeamento da fauna marinha brasileira. O pioneiro trabalho de LUEDERWALDT (1919) sôbre os manguezais de Santos, apresenta muitos dados fau-

Publ. n.o 247 do Inst. Ocean. da USP. nísticos úteis e interessantes ao estudo da região. A Tabela VI reproduz a lista dos animais encontrados por êsse autor (op. cit.) nos mangues de Santos.

\section{MATERIAL E MÉTODOS}

Foram realizadas 40 estações com o barco "Emília" de 9 a 11 de abril de 1964 (Fig. 1), usando um pegador de fundo tipo Van-Veen que colhe amostras de uma área de $1 / 30 \mathrm{~m}^{2}$. Em cada estação foi tomada apenas uma amostra, da qual foram separados os animais visíveis a olho nú. Usamos para isso duas peneiras com malha de $1 \mathrm{~mm}$ e de $0.5 \mathrm{~mm}$. Esses animais foram imediatamente fixados em álcool a $70 \%$.

Para termos idéia da distribuição das espécies bênticas na região estudada, utilizamos também os dados de nove dragagens realizadas na baía de Santos (Fig. 1) e de seis dragagens efetuadas em frente à Ilha de Santo Amaro (Fig. 2), bem como os de quatro coletas com um pegador Van-Veen de $0,2 \mathrm{~m}^{2}$, draga triangular e "otter trawl" realizados 


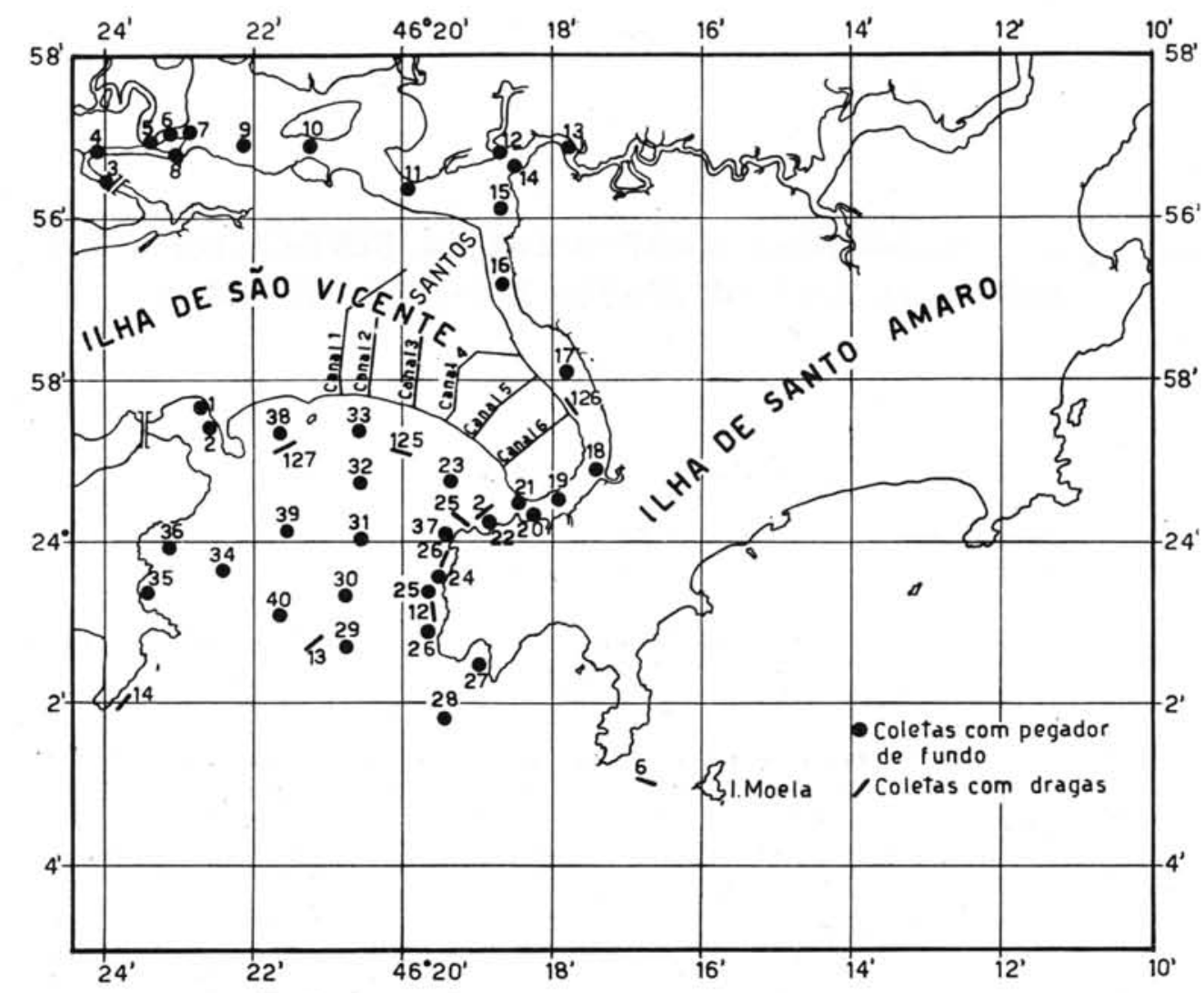

Fig. 1 - Região da baía e do canal de Santos, mostrando a posição das estações.

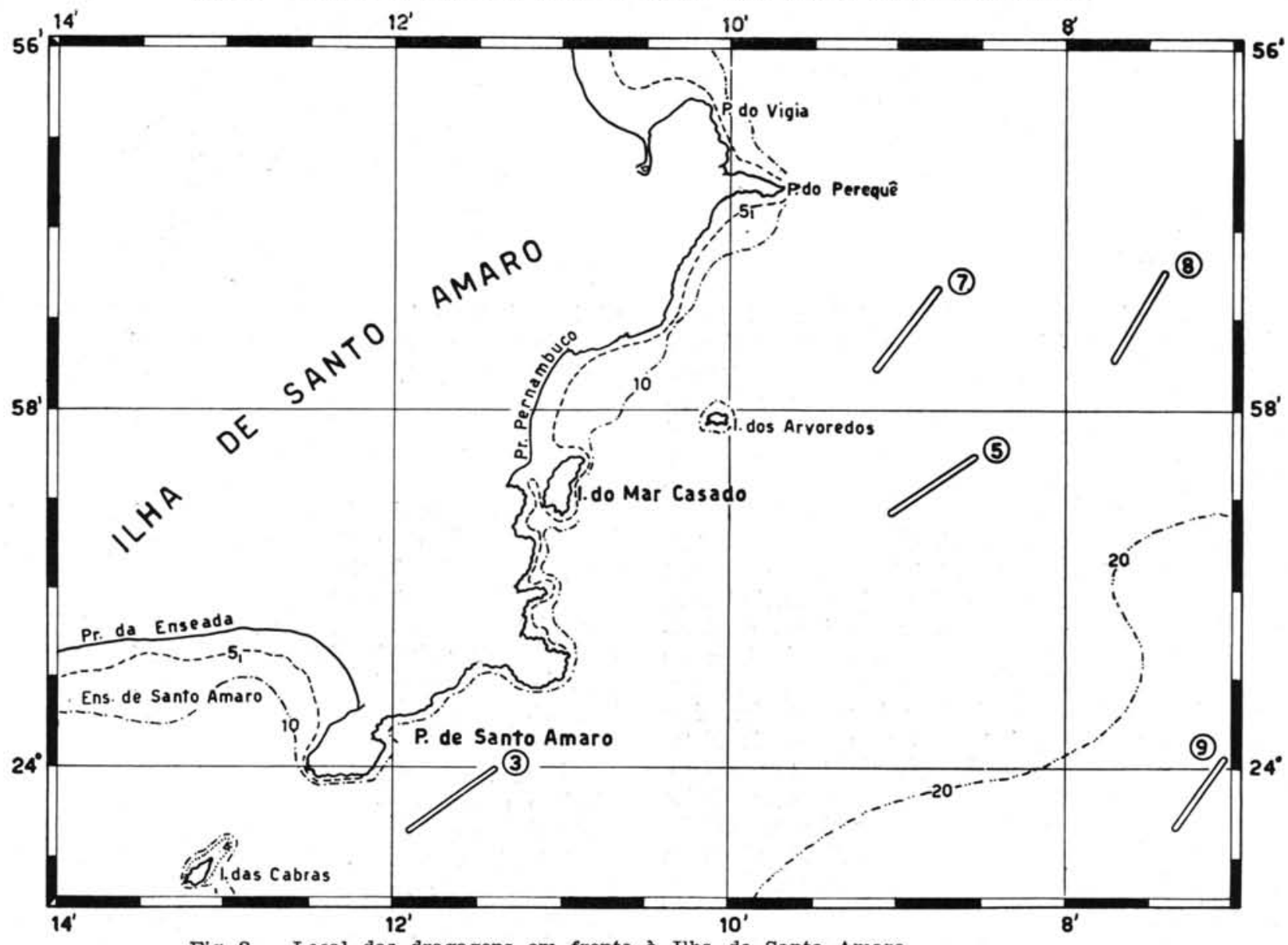

Fig. 2 - Local das dragagens em frente à Ilha de Santo Amaro. 


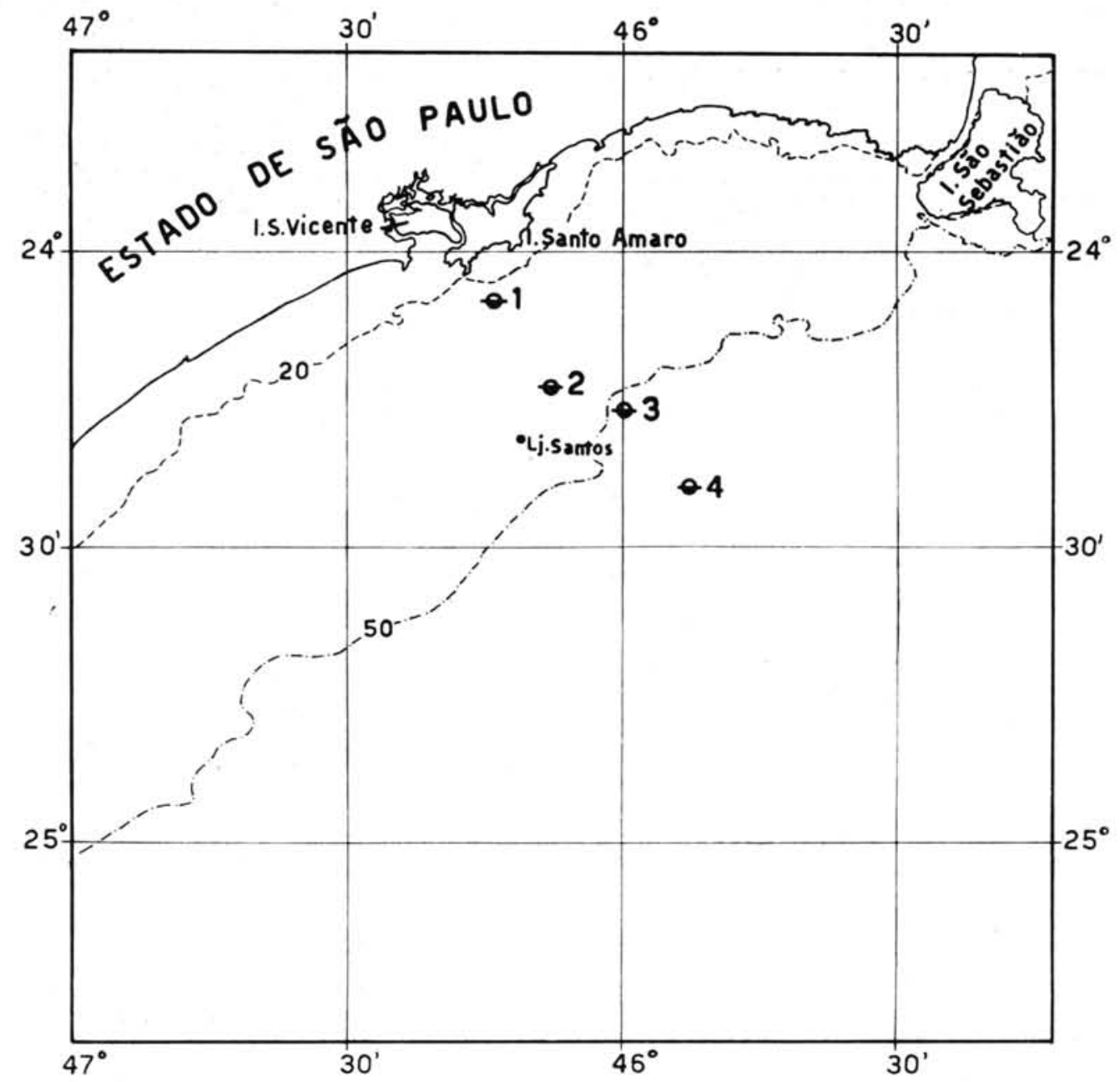

Fig. 3 - Posição das estações de hỉrografia e plâncton do Instítuto Oceanográfico da USP.

nos locais das estações fixas de plâncton e hidrografia do Instituto Oceanográfico da USP (Fig. 3).

Como na regiáo da baía e do canal de Santos tomamos apenas uma amostra em cada estação com o pegador Van-Veen de $1 / 30 \mathrm{~m}^{2}$, e, como essa amostra é insuficiente para fornecer informações quantitativas, os dados foram apreciados apenas qualitativamente, pois não se podia tirar conclusões sôbre a densidade e composição das possíveis associações presentes na região estudada.

Foram coletadas 149 espécies diferentes de animais bênticos, das quais 52 são poliquetas, 26 lamelibrânquios, 20 equinodermas, 17 crustáceos, 14 gastrópodes, 4 cnidários, além de 16 espécies de nemátodes, nemertineos, pantópodos, briozoários, enteropneustas e peixes (Tab. VII).

Êsses animais foram contados e enviados para especialistas a fim de serem classificados.

A determinação das espécies de equinodermas e de peixes estêve a nosso encargo, enquanto que as dos demais grupos foi feita pelos seguintes especialistas:

Dr. Edmundo Nonato

Polychaeta

Lic. José Luiz Moreira Leme

Dr. Gilberto Righi

Lamellibranchiata

Dr. L. B. Holthuis

Gastropoda

Lic. Frida Z. Ejchel

Dr. Plínio Soares Moreira

Crustacea (Decapoda)

Lic. Yoko Wakabara

Crustacea (Decapoda

Isopoda

Reptantia)

Dr. Ernst Marcus

Amphipoda

Dr. Tagea Björnberg

Bryozoa

Enteropneusta.

Muitas formas são classificadas só até gênero, pois estão ainda em estudo e serão objeto de trabalhos futuros.

Em cada estação foi tomada uma amostra do substrato para análise sedimentológica, bem como uma de água ao nível do fundo para determinação 
de salinidade e do teor de oxigênio dissolvido. Essas análises e dosagens foram efetuadas pela Secção de Química e Sedimentologia do Instituto Oceanográfico da USP.

A salinidade da água ao nível do fundo na região estudada aumenta do Casqueiro em direção à baía, sendo de $21,56-21,74^{\circ}$ oo no Casqueiro, 24,88 - 27,83\% no Canal da Bertioga e até $34 \%$, na baía (Fig. 4). O mesmo acontece com o oxigênio (Fig. 5). Esses dados para o Canal da Bertioga são mais elevados do que os obtidos por Lima \& VAzzoLER (1963) por que se trata, no presente caso, de água próxima ao fundo e não superficial como no caso daqueles autores.

Não existem até o presente, dados disponíveis sôbre gradientes de salinidade e sôbre a magnitude das modificações na salinidade da região aqui estudada. Não há também medidas sôbre a quantidade de água doce despejada na baía e canais.

$\mathrm{Na}$ Figura 6 mostramos a variação da temperatura na região estudada. A temperatura da água de fundo diminui do interior do Canal do Casqueiro em direção ao Canal de Santos, aumentando novamente para baixar de nôvo em direção à baía.

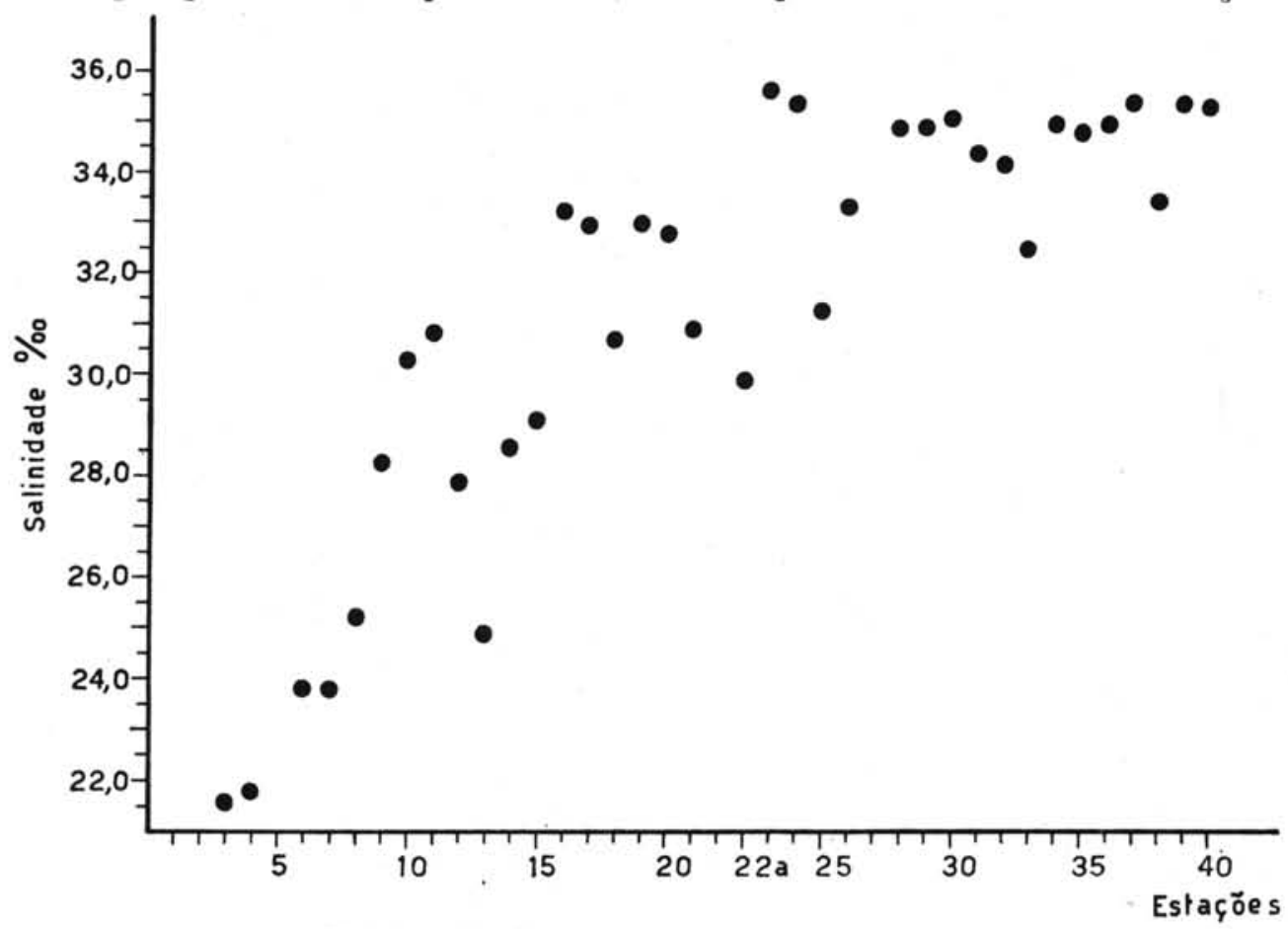

Fig. 4 - Salinidade da água a $1 \mathrm{~m}$ do fundo.

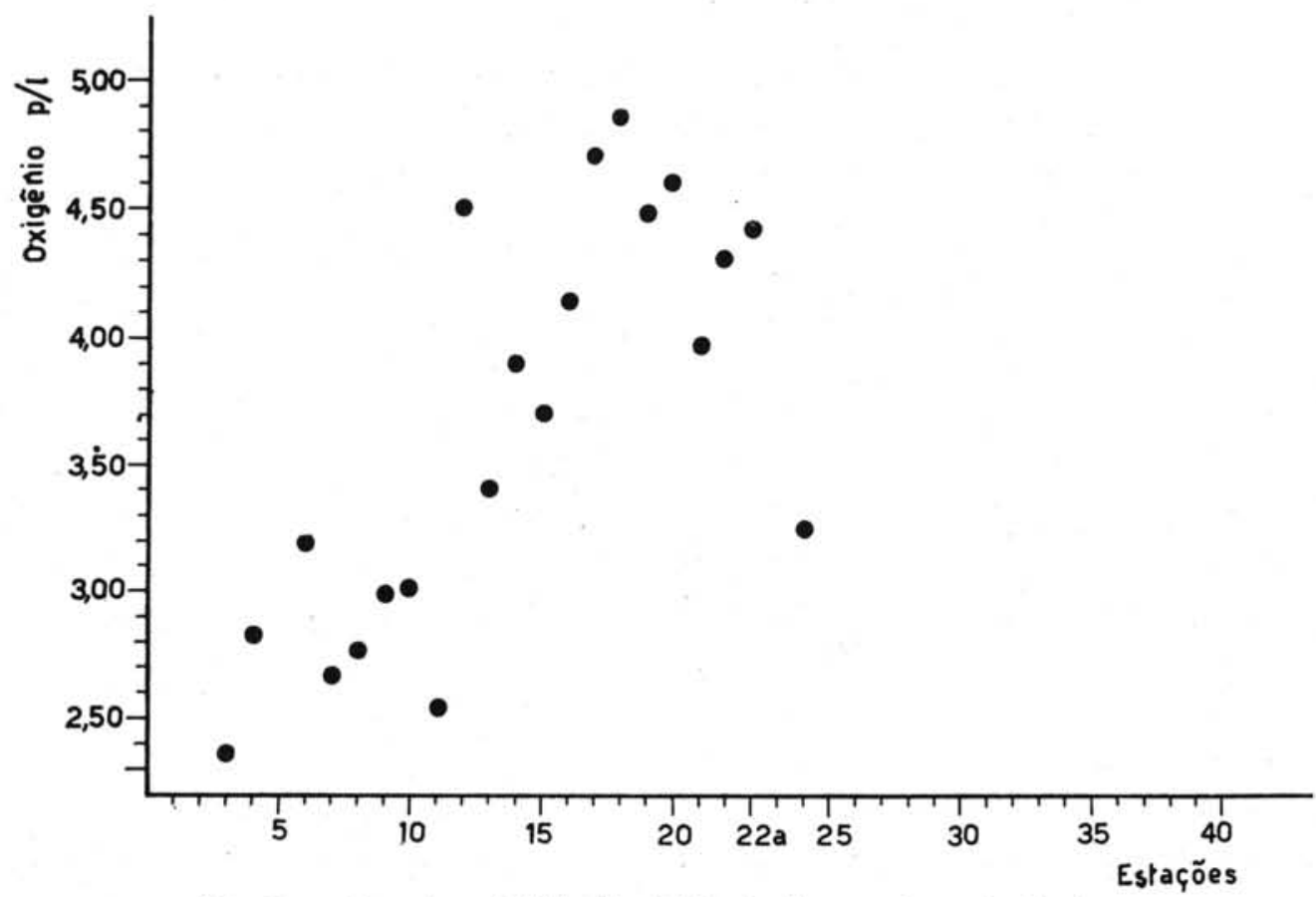

Fig. 5 - Teor de oxigênio dissolvido da água a $1 \mathrm{~m}$ do fundo. 
A Tabela V apresenta a análise dos sedimentos. Por êsses dados pode-se verificar que no Canal do Casqueiro, no Canal de Santos e no da Bertioga, assim como em diversas regióes da baía de Santos, predominaram sedimentos lodosos finos. $\mathrm{Na}$ parte sul da baía e nas praias ocorrem fundos arenosos. tróleo etc. que aumentam muito a poluição e fazem com que a transparência da água do Canal de Santos seja muito pequena. Já em 1952, Carvalho (p. 132) assinalara a dificuldade em colher plâncton na região próxima à entrada do Canal de Santos, devido a verdadeiros campos de nafta que muitas vêzes quase

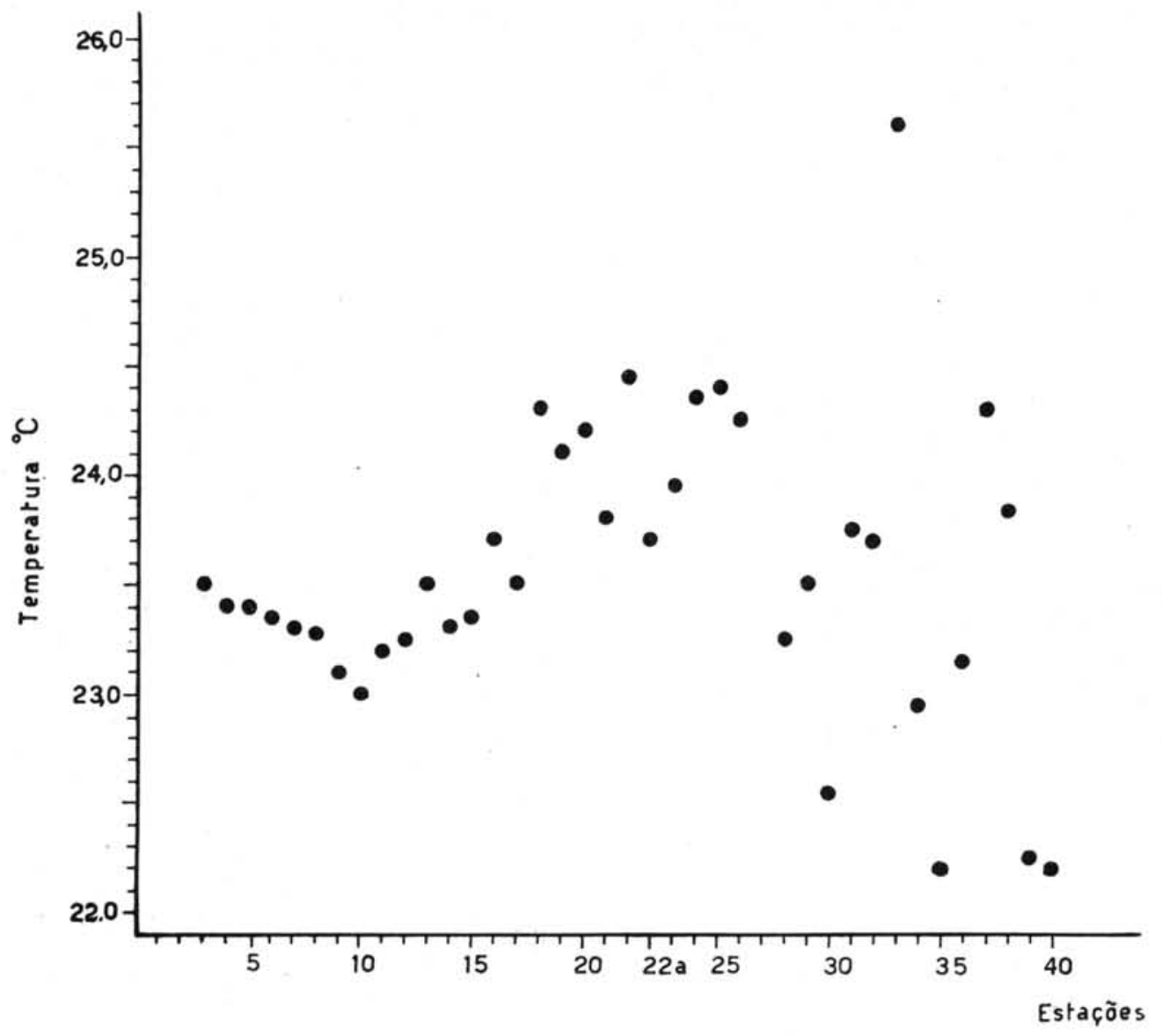

Fig. 6 - Temperatura da água a $1 \mathrm{~m}$ do fundo.

O mesmo se dá próximo aos costôes internos da Ilha de Santo Amaro. Na região das Est. 22 a 26 encontramos um fundo detrítico com conchas mortas.

$\mathrm{Na}$ região do mangue o solo é de lôdo ou de lôdo arenoso. Apresenta geralmente côr escura.

\section{A REGIÃO ESTUDADA}

Segundo REID (1961, p. 69) "An estuary has been defined as a body of water in which fresh water mixes with and measurably dilutes sea water. It is also described as the wide mouth of a river or arm of the sea where the tide meets the river currents, of flows and ebbs". Essa definição se aplica à região da baía de Santos (SP). Para o conhecimento geral da região é indispensável a consulta do trabalho geográfico coordenado por Azevero (1965) e o de AB'SÁBER (1965) sôbre a Serra do Mar e o litoral de Santos.

Além dos detritos e substâncias diversas oriundas dos manguezais e rios, são introduzidos na região restos domésticos, restos industriais, derivados de pe- inutilizaram suas rêdes de plâncton. A área em frente ao pôrto é contìnuamente dragada para fins de navegação, devido ao intenso assoreamento ali existente. 0 sedimento retirado é descarregado pelos chatôes próximo à Ponta do Itaipú.

Em frente à baía de Santos pratica-se intensa captura comercial de peixes e camarões. A sua flora ficológica é bem conhecida (JoLY, 1957), mas relativamente pouco se sabe sôbre sua fauna marinha. Os hidrozoários, turbelários, pantópodos, briozoários e equinodermas são os grupos melhor conhecidos. Quanto aos demais grupos bênticos, muito pouco ou mesmo nada foi publicado.

Entre os principais trabalhos que incluem ou se referem a espécies da região de Santos, temos os seguintes:

Foraminiferos: Carvalho \& Chermont, 1952.

Hidrozoârios: Vannucci, 1946, 1949, 1951, 1954;

Poliquetas: Mangum, 1966;

Nemátodes: Gerlach, 1954;

Turbelários: Marcus, 1947, 1948, 1949, 1952, 1954; Corrêa, 1949; 
Anisópodes: Lang, 1956;

Calianasideos: Rodrigues, 1965;

Estomatópodes: Manning, 1966;

Harpacticoides: Carvalho, 1952;

Decapodes: Neiva \& Wise, 1963; Vieira, 1947; Kretz \& Bücherl, 1940; Sawaya, 1944; Righi, 1967b;

Pantópodes: Marcus, 1940, 1962;

Moluscos em geral: Lange de Morretes, 1949;

Opistobranquios: Marcus, 1955a, 1955b, 1957; Marcus \& Marcus, 1961, 1964;

Gastrópodes: Marcus \& Marcus, 1963a, 1963b; 1965;

Lamelibranquios: Lima \& Vazzoler, 1962 (Ostras), Klappenbach, 1965;

Amphineura: Righi, 1967a;

Foronideos: du Bois Raymond Marcus, 1949, Forneris, 1959 .

Briozoârios: Marcus, 1937, 1938a, 1938b, 1939; Corrêa, 1948; du Bois Raymond Marcus, 1950, 1957; Guimarães \& Rosa, 1941;

Equinodermas: Bernasconi, 1956; Tommasi, 1957, 1958, 1965a, 1966a, 1966b;

Enteropneustas: Björnberg, 1959;

Acrania: Sawaya \& Carvalho, 1938, 1950;

Bagres: Tommasi, 1965b.

Os seguintes trabalhos são básicos para o estudo da oceanografia geral da região abrangida no presente trabalho. BrasiL. Ministério da Marinha 1957; 1958; EMílsSON 1955; 1956, 1961; JAPÃO, 1958 e Silva, 1952.

\section{OBSERVAÇÓES SÔBRE A FAUNA DAS PRAIAS E DO MANGUE}

Nas proximidades do Canal 2 (Fig. 1) encontramos na zona das marés superior, fundo de areia, numerosos lamelibrânquios da espécie Mesodesma mactroides que podem ser coletados na maré baixa a cêrca de $5-10 \mathrm{~cm}$ de profundidade, no sedimento. Na região do Canal 1 (Fig. 1) durante vários anos temos encontrado na praia, também na zona das marés, numerosos Donax hanleyanus, Tivela mac. troides e o pinoterídeo Pinixa angeloi. Um pouco mais para o fundo, cêrca de metro e meio a dois metros, encontramos periòdicamente densas populações de Mellita quinquiesperforata. Próximo à ilha Urubuqueçaba, na zona das marés, fundo de areia, ocorrem numerosos Callianasa major.

$\mathrm{Na}$ parte interna do Canal de Santos e no Canal da Bertioga ocorre um manguezal (LuEdERwaLdT, 1919) constituído principalmente por Rhizophora mangle, Avicennia schaueriana e Laguncularia racemosa e as invasoras Hibiscus tiliaceus, Spartina bra. ziliensis etc. Nessa região, o fundo é de lôdo arenoso rico em matéria orgânica. Nêle ocorrem com maior freqüência os caranguejos: Uca vocator, Ucides cordatus, Goniopsis cruentata, Cardisoma guanhumi e o siri Callinectes danai. Nos ramos e caules do mangue são encontrados os caranguejos: Aratus pisoni e Metasesarma rubripes. $\mathrm{Na}$ região do Canal do Casqueiro (Fig. 1) nas partes baixas dos troncos e galhos do mangue ocorrem numerosos indivíduos do gasterópode Melampus coffeus (ver MARcus \& MARCus 1965, sôbre a morfologia e biologia desta espécie).

\section{OBSERVAÇOESS SOBRE AS ESPÉCIES DE POLIQUETAS}

Os poliquetas foram os animais mais abundantes em tôda a região da baía e do canal de Santos, representando $46,94 \%$ do número total de espécies bênticas coletadas.

As estações em que ocorreu maior número de es. pécies de poliquetas foram as de $n .^{\circ} 20$ e 30 , com 15 espécies cada, seguidas das de n. ${ }^{\circ} 19,10$ e 4, com 14, 13 e 12 espécies, respectivamente. Com 10 espécies temos as estações n. ${ }^{\circ} 24$ e 29.

As espécies de poliquetas mais freqüentes foram as seguintes:

\begin{tabular}{l|c|c}
\hline \multicolumn{1}{c|}{ Espécie } & $\begin{array}{c}\text { N.o de Es- } \\
\text { tações onde } \\
\text { ocorre a } \\
\text { espécie }\end{array}$ & $\begin{array}{c}\text { \% de ocor- } \\
\text { rência em } \\
\text { relaçõo ao } \\
\text { n.o de } \\
\text { estações }\end{array}$ \\
\hline Audouinia tentaculata & 13 & 32.5 \\
Onuphis quadricuspis & 12 & 30 \\
Owenia fusiformis & 12 & 30 \\
Thelepus setosus & 10 & 25 \\
Telepsavus costarum & 9 & 22.5 \\
Magelona sp. & 9 & 22.5 \\
Loandalia americana & 8 & 20 \\
Poecilochaetus australis & 8 & 20 \\
Clymene sp. & 7 & 17.5 \\
Laonice japonica & 7 & 17.5 \\
Ninöe sp. & 7 & 17.5 \\
Diopatra tridentata & 6 & 15 \\
Ancystrosylis bassi & 5 & 12.5 \\
Halosydnella braziliensis & 5 & 12.5 \\
Prionospio pinnata & 5 & 12.5 \\
& & \\
\hline
\end{tabular}

As seguintes espécies foram coletadas tanto na baía de Santos como no Canal de Santos:

Audouinia tentaculata
Onuphis quadricuspis
Owenia fusiformis
Thelepus setosus
Telepsavus costarum
Diopatra tridentata
Loandalia americana
Magelona sp.
Marphysa sanguinea
Nereis sp.
Pherusa sp.
Pista sp.
Poecilochaetus australis
Prionospio pinnata
Scoloplos treadwelli

As seguintes espécies coletadas na baía de Santos não ocorreram nas amostras tomadas no Canal de Santos:

Glycera sp.
Goniada brunnea
Laonice japonica
Leanira sp.
Ninöe sp.
Spiophanes missionensis

SANDERS (1958) verificou que em fundo de areia ocorrem predominantemente espécies bênticas que capturam alimento por filtragem da água do mar ("filter feeding") e que em fundo de lôdo predominam as que comem material orgânico depositado no sedimento ("deposit feeding").

Audouinia tentaculata (Cirratulidae) foi coletado em 13 estações e ocorreu predominantemente 
em sedimento com granulação de $105-55 \mu$. A estação onde essa espécie ocorreu em maior densidade foi a de . $^{\circ} 18$, que apresenta $70 \%$ do sedimento no intervalo $2.000-44 \mu$ e $58.6 \%$ no intervalo $105-55 \mu$ de granulação.

GEORGE (1964) estudou a biologia dessa espécie e verificou que come indiscriminadamente detritos das camadas superficiais de lôdo, inclusive, provàvelmente, jovens de sua própria espécie. Para $\mathrm{S}_{\mathrm{A}}$ vilov (1959) os Cirratulidae são comedores de detritos orgânicos do sedimento.

Considerando como SANDERs (op. cit.) todos os comedores de detritos ou substâncias orgânicas do sedimento como pertencentes a um único grupo, obtivemos nas presentes coletas, além da espécie precedente, outras pertencentes a famílias consideradas como dêsse tipo de alimentação por. SAvilov (op. cit.) ou seja: Ampharetidae: Ampharete sp. nas Est. 22, 30 e 33; Terebellidae: Pista sp. nas Est. 10, 16, 24, 30; Spionidae: Laonice japonica nas Est. 19, 23, 25, 28, 30, 37: Polydora sp. na Est. 29: Prionospio pinnata; nas Est. 14, 29-31, 40 e Sphiophanes missionensis nas Est. 22A, 29-31. Com exceção de $P$. pinnata que foi coletada na Est. 14, as demais espécies de Spionidae ocorreram principalmente da entrada do canal de Santos para a baía Maldanidae: Clymene sp. e Clymenella cincta, nas Est. 19 a 23 , Onuphidae: Onuphis quadricuspis coletada desde o Casqueiro até a linha da Est. 29 a 33 e os Orbinidae: Nainereis setosa e Scoloplos treadwelli coletados do canal até a linha das Est. 29 a 33 (Nainereis).

Poecilochaetus australis foi encontrado por Nonato (1963, p. 34) apenas em lôdo arenoso negro, contendo $30 \%$ em pêso constituido por minerais metálicos com ferro e titânio. Isso levou àquele autor a acreditar que "essa espécie ocupa nichos ecológicos muito pequenos e raramente acessíveis". Esta espécie é representada exclusivamente por formas jovens, presumivelmente pós-metamorfoseadas e ocorrem predominantemente nas amostras do Canal de Santos, tendo sua maior densidade sido observada nas Est. 13 e 16, ou seja, naquelas que apresentam sedimento bem variado (com fração granulométrica superior a $2.000 \mu)$, alto teor de calcáreo da fração maior de $44 \mu \mathrm{e}$ alto teor de Ca no sedimento.

Como se verifica na Tabela $\mathrm{V}$, predominam na presente região estudada, sedimentos com fração granulométrica contida no intervalo $105-53 \mu$. Comparando os dados sedimentológicos dessas Estações com as Est. J. Q, O e L de SANDERs (1958), verifica-se que como na região de Buzzards Bay (USA) estudada por êsse autor, na baía de Santos em sedimentos finos, predominam espécies comedoras de matéria orgânica do sedimento.

Owenia fusiformis, um "ciliary feeder" foi coletado apenas em 10 estações, enquanto que os "deposit feeders" o foram em 23 estações.

Isso era de se esperar, pois na região do canal de Santos e mesmo em ampla parte da baía de Santos, predominam fundos de lôdo.

Segundo REISH (1963, p. 325) Marphysa sanguinea ocorre em fundo de silt no terço superior da baía de San Quentin. Na região de Santos essa es- pécie ocorre tanto no canal (Est. 7 e 19) como na baía (Est. 30 e 37) e não sòmente em fundo de silt. Os Eunicidae, aos quais pertencem Eunice sp. e Marphysa sanguinea, são conhecidos como predadores carnívoros. Segundo SANDERS et al. (1963) os Nereidae, Phyllodocidae, Glyceridae, Lumbrinereidae e os Onuphidae são onívoros ou "detritus feeders". Para outros autores (Hunt 1926; Yonge 1928), são carnívoros. Nas presentes amostras obtivemos diversos representantes dessas famílias, ou seja: Lumbrinereidae: Lumbrinereis minima, Ampharetidae: Ampharete sp. Nephthyidae: Nephthys sp. e Aglaophanus sp. Glyceridae: Glycera sp. e o Onuphidae. Onuphis quadricuspis. Com exceção da última, houve uma nítida tendência dessas espécies ocorrerem com maior freqüência da Est. 19 (situada na entrada do Canal de Santos) para a regiáo da baía de Santos, ou seja, em estações onde o sedimento foi mais arenoso.

\section{OBSERVAÇÕES SÔBRE AS ESPÉCIES DE MOLUSCOS}

Pode-se verificar da Tabela VII, que o número de espécies de gastrópodes presente nas amostras foi pequeno e pouco variável, enquanto que os lamelibrânquios, ainda que representados por pequeno número de espécies diferentes mostraram um aumento gradual do número de espécies do canal em direção ao mar aberto.

Em fundo detrítico e em fundo de areia e lôdo, o número de espécies de moluscos foi maior do que em fundo de lôdo.

O número de espécies de lamelibrânquios foi maior nas Est. 37 (9 espécies), e 24 (6 espécies). $\mathrm{O}$ número de indivíduos de gastrópodes foi sempre pequeno, salvo onde ocorreu Littoridina australis var. nana (ver MARcus 1963b, p. 33-54, fig. 39-53 sôbre a anatomia e biologia desta espécie). Esta espécie é um lamelibrânquio da família Pholadidae, (provàvelmente Cyrtopleura costata) e foi obtida apenas nas estações mais interiores. L. australis var. nana ocorreu apenas na região do Canal do Cas: queiro (Est. 3 a 8), no Canal da Bertioga (Est. 14) e na entrada da baía de São Vicente (Est. 2). Segundo Marcus \& Marcus (1965), na região de Cubatão (Fig. 1) ocorrem também L. miaulis e $L$. charruana.

O sedimento da Est. 3 apresentou forte cheiro de ácido sulfídrico e o único animal vivo encontrado foi a L. australis var. nana. Para o interior do Canal do Casqueiro, as condições ambientais apresentam-se progressivamente em situação de pessimus (AlleE et al. 1963, p. 212-215). Da entrada do canal do Casqueiro até a região da ponte da Via Anchieta (Fig. 1) parece-nos que teriamos progressivamente uma curva do número de espécies do tipo litoral apresentada por SANDERS (1965, p. 85, fig. 1). Na Est. 3 essa curva seria uma linha perpendicular à base, pois teriamos apenas uma espécie. Mais para o interior, provàvelmente em condições de pessimus só teriamos bactérias e talvez microfauna. 
O elevado teor de Ca no sedimento da Est. 7 é, em grande parte, devido aos fragmentos de conchas de L. australis var. nana.

O lamelibrânquio Chione cancellata e o gastrópode Anachis obesa tiveram em linhas gerais uma distribuição bastante semelhante. Ocorrem na baía, entram no canal de Santos e no canal da Bertioga mas não foram coletados da Est. 11 para o interior do canal. Sendo Chione cancellata pertencente a um grupo de lamelibrânquios filtradores, a distribuição apontada acima está aparentemente ligada às condições ambientais, pois quanto mais para o interior do canal de Santos, menor é a circulação de água e portanto as condições são menos favoráveis à ocorrência de filtradores.

Os telináceos constituem um grupo de lamelibrânquios reconhecidamente "detritus-feeding" e muitas vêzes citados como ocorrendo em sedimentos arenosos. Os representantes dêsse grupo obtidos em nossas amostras, ou seja, Tellina alternata, Tellina exilis e Arcopagia sp. foram coletados principalmente no lado sul da baía, após a linha formada pelas Est. 20 a 33 , onde além da salinidade da água do mar ser mais elevada, ocorreu um sedimento bem mais arenoso do que no resto da baía (Tab. V) e no canal de Santos. Apenas Tellina alternata ocorreu na entrada do canal de Santos e também na Est. 4.

$\mathrm{Na}$ mesma região da baía de Santos, onde ocorreram os telináceos citados anteriormente, foram encontrados também as seguintes espécies: Anadara braziliensis (Arciidae), Mactra iehringi e Mactra petiti (Mactridae).

Macoma tagelliformis pertencente a um gênero de espécies comedoras de detritos orgânicos do sedimento ocorreu apenas nas estações do canal de Santos (Est. 5, 16 e 20).

\section{OBSERVAÇÕES SOBRE AS ESPÉCIES DE EQUINODERMAS}

A região compreendida entre a ponta dos Limões e a Ilha das Palmas (Fig. 1), apresentou um fundo detrítico com conchas mortas. Nessa região é que ocorreu o maior número de espécies de equinodermas de tôda a área estudada (Dragagem 26, Est. 24 a 37). Essas espécies foram as seguintes:

\section{Crinoidea: Tropiometra carinata carinata \\ Asteroidea: Astropecten braziliensis Coscinasterias tenuispina Echinaster braziliensis \\ Echinoidea: Lytechinus variegatus \\ Ophiuroidea: Micropholis atra \\ Amphipholis januarii \\ Hemipholis elongata \\ Ophiactis lymani \\ Ophiothrix angulata \\ Ophioderma januarii}

Tropiometra carinata carinata, Coscinasterias tenuispina, Echinaster braziliensis e Ophiothrix angulata são espécies de fundos duros. Lytechinus variegatus ocorre em fundos duros e em moles da baía mas não no canal de Santos.
Astropecten braziliensis é comum na plataforma em frente à baía, mas nela é bem raro. Luidia senegalensis ocorre em tôda a baía, principalmente próximo à Ilha Porchat e entra no canal de Santos até a Est. 19.

Na região da baía e do canal de Santos ocorrem duas espécies de Ophiactis: $O$. lymani, encontrada em fundos moles e, mais raramente, sôbre tubos de poliquetas e $O$. savignyi, encontrada nos "tapetes" de algas calcáreas, (Porphyra, Jania etc.) dentro de esponjas, sob pedras etc.

Ophiothrix angulata vive entre algas, entre e sob pedras e também no interior de esponjas.

Dos Amphiuridae, apenas Hemipholis elongata e Micropholis atra ocorrem em densidades elevadas na baía de Santos, principalmente na regiāo ao redor da Ilha das Palmas. Dessas duas espécies, a que ocorreu em estações mais internas no canal foi Micropholis atra (até a Est. 18), o que sugere ser mais euriéca do que Hemopholis elongata.

Ophioderma januarii ocorreu no fundo detrítico da região das Est. 24 a 37 . Periòdicamente é encontrada em grande número atirada nas praias próximas da Est. 23.

\section{OBSERVAÇÕES SOBRE AS ESPÉCIES DE CRUSTÁCEOS}

O número de espécies de crustáceos obtido nas amostras foi sempre diminuto, tendo sido maior na região da estação 24 e das radiais 128 a 132 , onde ocorre um fundo detrítico no qual encontramos as seguintes espécies:

Apiomithrax violaceus
Euryplax nitidus
Hepatus pudibundus
Hexapanopeus angustifrons
Hexapanopeus paulensis
Hexapanopeus schmitti
Heterocrypta granulata
Heterocrypta lapidea
Inachioides obtusus
Mesorhaea sexpinosa
Notolopas brasiliensis
Paguristes tortugae
Pagurus sp.
Porcellana sp.
Pilumnus caribaeus

\section{OUTRAS OCORRENCIAS}

O briozoário lunulitiforme Discoporella umbellata foi encontrado na região das Est. 22, 23 e 38, parecendo que não ocorre no canal. Na Est. 22 ocorreu, em grande número, um actiniário do tipo "Edwardsia", que foi coletado apenas em duas estações, ambas na entrada de canais, sendo que na Est. 22 o foi em grande número.

SANDERS (1960) e SANDERS et al. (1963) regis. traram um antozoário semelhante ao presente em suas estações, mas sempre em número muito pequeno (1 e 4 exemplares).

Já Muus (1964) observou numa comunidade de Venus, (sempre associada com fundo de areia, apud 
Thовson 1957, p. 485) 500 "Edwardsia" por m Como se verifica da Figura 7, a Est. 22 apresenta um sedimento de areia com pouco lôdo o que concorda com o tipo de fundo onde ocorre a comunidade de Venus.

\section{OBSERVAÇŌES SOBRE AS ESPÉCIES COLETADAS NOS ARREDORES DA BAfA DE SANTOS}

Várias espécies coletadas nas dragagens em frente à Ilha de Santo Amaro (Fig. 2, Tab. III), não o foram nas estações (com pegador ou com draga) realizadas na região da baía de Santos. Essas espécies são as seguintes:

\section{Anadara bivalvis} Nuculana electa Pecten tehuelchus

\section{Dorsanum moniliferum Persephona punctata Amianthis purpurata}

A Figura 3 apresenta a posição das estações de hidrografia e plâncton do Instituto Oceanográfico da USP onde realizamos, em 3 de novembro de 1965, várias coletas com pegador de fundo, ao longo de uma secção de Santos para sueste. Apesar da maioria dos poliquetos obtidos nessas estaçôes, ainda estar classificada apenas até o gênero, várias das espécies dos demais grupos já o foram até espécie. Dêsse material, o que mais chama a atenção é a ocorrência de Discoporella umbellata. A estação onde observa. mos maior densidade dêsse briozoário foi a II (cêrca de 2220 colonias $/ \mathrm{m}^{2}$ ) tendo ocorrido em menor densidade na Est. III e em muito pequena na Est. IV. $\mathrm{Na}$ baía de Santos, como vimos anteriormente, essa espécie foi coletada em pequeno número. É também interessante assinalar o elevado número de siris (Portunus (Achelous) spinicarpus) coletados na Estação IV (Tab. IV).

Algumas espécies coletadas nestas estações não o foram na baía de Santos. Essas espécies são as seguintes:

$\begin{array}{ll}\text { ESTAÇÃo I } & \text { Olivella verraux } \\ \text { ESTAÇÃo II - } & \text { Amphipholis subtilis. } \\ & \text { Spio sp. } \\ \text { ESTAÇÃo III - } & \text { Arenphiodia riisei. } \\ & \text { Oliva sayana } \\ & \text { Olivella jaspidea } \\ & \text { Strombus goliatti } \\ & \text { Fusinus mucronatus } \\ & \text { Conus sp. } \\ & \text { Polinices hepaticus } \\ & \text { Persephona punctata } \\ & \text { Portunus (Achelous) spinicarpus } \\ & \text { Sicyonia typica } \\ & \text { Hemisquilla brasiliensis. } \\ \text { Asychis sp. } \\ \text { Terebra protecta } \\ \text { Murex antillarum(?) } \\ \text { Portunus (Achelous) spinicarpus } \\ \text { Hemisquilla brasiliensis } \\ \text { Squilla brasiliensis } \\ \text { Luidia scotti } \\ \text { Tethyaster vestitus } \\ \text { Amphiura complanata } \\ \text { Amphiura flexuosa. }\end{array}$

Além do possível efeito da salinidade mais baixa, maior fração de silt e argila no sedimento da região da baía de Santos, o aumento da profundidade deve, sem dúvida, ser levado em conta nas diferenças encontradas entre a fauna da baía e a das estações na plataforma, especialmente no que se refere às Est. III e IV.

\section{OBSERVAÇÓES GERAIS}

Ainda que os presentes dados sejam preliminares, sugerem a existência de diversos grupos de estações na região do canal e da baía de Santos, caracterizados cada um por espécies mais numerosas em cada amostra. São provàvelmente correlacionados, com a textura do sedimento e com a salinidade da água de fundo. (A importância da granulometria na distribuição das espécies bênticas em regiões interiores, como a presentemente estudada, foi bem evidenciada por Beanland (1940), Holme, (1949) e Sanders (1958). Citamos a seguir êsses grupos, apresentando as características ambientais mais importantes e as espécies mais numerosas em cada um.

O primeiro dêsses grupos (Est. 1, 3, 4, 7, 8) apresenta fundo de lôdo arenoso com cheiro de ácido sulfídrico, água com baixa salinidade e baixo teor de oxigênio. Há um progressivo estabelecimento de condições de pessimus e conseqüente redução da infauna para o interior do canal do Casqueiro. Aí ocorre o gastrópode Littoridina australis var. nana em elevada densidade. 0 segundo grupo (Est. 2, 5, 10, 13, 16, $18,19,33$ ) possui fundo de lôdo arenoso sem cheiro de ácido sulfidrico, água com salinidade progressivamente maior em direção à baía de Santos e apresenta numerosos exemplares de Audouinia tentaculata e de Poecilochaetus australis. O terceiro grupo (Est. $22,24,25$ e 32 ) se caracteriza por apresentar um fundo mais arenoso, com conchas mortas (Est. 24), e pela ocorrência de ofiuróides. Aparentemente, esta área é a mais rica em espécies de animais bênticos de tôda a região da baía e canal de Santos. Em seu estudo da baía de Greenwich, Stickney \& Stringer (1957) encontraram também maior número de espécies nas estações cujo sedimento apresentava diâmetro médio maior. $\mathrm{O}$ quarto grupo (Est. 28 a 31 e 40) apresenta um fundo de areia lodosa, a ocorrência de Ninoë sp. e de Prionos. pio pinnata e está aparentemente sob menor influência da água oriunda do canal de Santos do que as anteriores. O quinto grupo (Est. 9, 12 e 39) apresenta os poliquetas Loandalia americana e Owenia fusiformis e apresenta um fundo de lôdo arenoso. Além dêsses grupos de estações poderiamos citar mais duas áreas bem distintas: $1 .^{\mathrm{a}}$ ) a faixa de praias arenosas que circundam a baía e na qual são comuns os lamelibrânquios Donax hanleyanus, Mesodesma mac. troides e Tivela mactroides, bem como o talasinídeo Callianassa major. Dois hipídeos e o pinoterídeo Pinixa angeloi são freqüentemente encontrados nessas praias. A zonação faunística dessas praias é muito semelhante à observada por RoDRIgues (1959) para as praias arenosas da Ilha Margarita (Venezuela); $2 .^{\mathrm{a}}$ ) a região de mangue, localizada principalmente na parte mais interna dos canais de Santos e da Bertioga, onde ocorrem numerosos decápodes, como por exem- 
TABELA I - Eficiência dos aparelhos utilizados na captura de espécies bênticas

ESTAÇÃO II

\begin{tabular}{l|c|c|c}
\hline $\begin{array}{c}\text { Espécies enumeradas em } \\
\text { tamanho crescente }\end{array}$ & $\begin{array}{c}\text { Pegador de fundo } \\
\left(0.2 \mathrm{~m}^{2}\right)\end{array}$ & $\begin{array}{c}\text { Draga trian- } \\
\text { gular }(80 \mathrm{~cm})\end{array}$ & $\begin{array}{c}\text { "Otter traw1" } \\
\text { (8 m de bôca) }\end{array}$ \\
\hline & 219 & 36 & 0 \\
Discoporella umbellata & 0 & 2 & 0 \\
Calyptraeidae & 3 & 0 & 0 \\
Stylarioides sp. & 3 & 0 & 0 \\
Nemertineo & 0 & 2 & 2 \\
Oliva sayana & 0 & 5 & 0 \\
Murex senegalensis & 0 & 0 & 4 \\
Sicyonia typica & 0 & 0 & 3 \\
Penaeus brasiliensis & 0 & 0 & 22 \\
Prionotus alipionis & & & 0 \\
\hline
\end{tabular}

ESTAÇÃO IV

\begin{tabular}{|c|c|c|c|}
\hline $\begin{array}{l}\text { Espécies enumeradas em } \\
\text { tamanho crescente }\end{array}$ & $\begin{array}{l}\text { Pegador de fundo } \\
\qquad\left(0.2 \mathrm{~m}^{2}\right)\end{array}$ & $\begin{array}{l}\text { Draga trian- } \\
\text { gular }(80 \mathrm{~cm})\end{array}$ & $\begin{array}{l}\text { "Otter trawl" } \\
\text { ( } 8 \mathrm{~m} \text { de bôca) }\end{array}$ \\
\hline $\begin{array}{l}\text { Discoporella umbellata } \\
\text { Asychis sp. } \\
\text { Goniada sp. } \\
\text { Ninöe sp. } \\
\text { Nephthys sp. } \\
\text { Onuphis quadricuspis } \\
\text { Amotripane sp. } \\
\text { Portunus (Achelous) } \\
\quad \text { spinicarpus } \\
\text { Penaeus brasiliensis } \\
\text { Hemisquilla brasiliensis } \\
\text { Prionotus beanni }\end{array}$ & $\begin{array}{l}0 \\
0 \\
2 \\
5 \\
5 \\
1 \\
0 \\
0 \\
\\
\\
0 \\
0 \\
0\end{array}$ & $\begin{array}{r}5 \\
10 \\
0 \\
17 \\
6 \\
5 \\
6 \\
0 \\
\\
0 \\
0 \\
0\end{array}$ & $\begin{array}{r}0 \\
0 \\
0 \\
0 \\
0 \\
0 \\
0 \\
268 \\
6 \\
6 \\
14\end{array}$ \\
\hline
\end{tabular}

plo: Aratus pisoni, Metasesarma rubripes (arboricolas), Cardisoma guanhumi, Goniopsis cruentata, Pachygrapsus gracilis, Uca uruguayensis, Uca mordax etc., o gastrópode Melampus coffeus etc.

\section{OBSERVAÇÕES SÔBRE OS APARELHOS BENTICOS}

E interessante comparar a eficiência dos aparelhos bênticos utilizados na captura das espécies mais numerosas obtidas nas Est. II e IV (Tab. I).

Pelos dados anteriores verificamos que, quanto maior e mais ativa a espécie bêntica (megabentos no conceito de GILAT, 1963) mais eficientes foram o "otter trawl" e a draga em sua captura e menos eficiente foi o pegador. Para espécies pouco ou não vageis e espécies pequenas (macro e meiobentos no conceito de Gilat, op. cit.) como a Discoporella umbellata, o pegador foi muito mais eficiente.

Êsses resultados demonstraram não só a diferença de eficiência dos três tipos de aparelhos na captura das espécies bênticas em relação ao seu tamanho e vagilidade, como também confirmam mais uma vez (McIntyre, 1956) a necessidade da utilização de aparelhos diversos para um perfeito levantamento da fauna bêntica de uma regiáo, a fim de termos os indivíduos de todos os níveis tróficos da associação estudada.

\section{SUMMARY}

The Bay of Santos may be considered as an estuarine region where polution caused by industry refuse, sewage etc. is growing day by day. Besides this, the opening of a new canal to permit navigation for COSIPA (Companhia Siderúrgica Paulista) will probably cause increased alteration in the biological conditions observed at present time.

Forty stations were occupied and operated with a Van-Veen $1 / 30 \mathrm{~m}^{2}$ bottom grab and 4 Van-Veen $1 / 5 \mathrm{~m}^{2}$ dredges as well as 15 triangular dredge hauls. 149 species of benthic animals were collected, of which 52 are polychaets, 26 lamellibranchs, 20 echinoderms, 17 crustaceans, 14 gastropods, 4 cnidarians and 16 belonging to other different groups.

An inventory of the main papers already published was done, dealing with the benthic fauna of this region.

On the sand beaches are very common the lamillibranchs Mesodesma mactroides, Domax hanleyanus and Tivela mactroides and the talasinid Callianasa major. More seldom we could observe the pinnotherid Pinixa angeloi and two hypidians.

On the mangroves numerous decapods occur, such as Aratus pisoni, Metasesarma rubripes (arboricolous), Cardisoma guanhumi, Goniopsis cruentata, Pachygrapsus gracilis, Uca leptodactyla, Uca uruguayensis, Uca mordax, the gastropod Melampus coffeus etc.

Polychaets were most abundant animals throughout all the region under study. The most frequent species were Audouinia tentaculata, Onuphis quadricuspis, Owenia fusiformis and Telephus setosus. Poecilochaetus australis occurred mostly in the samples collected in the Santos Channel. In the innermost 
parts of the region under study, especially in the Casqueiro Channel, very dense populations of Littoridina australis var. nana occurred. In the southern parts of the bay several species of telinaceous occurred. The most frequent ophiurans were Ophiactis lymani, Hemipholis elongata and Micropholis atra.

The bottom type where the major number of species occurred was a detritic one and was close to the internal rocky coasts of Santo Amaro Island.

Several species collected on the shelf off the Bay of Santos, did not actually occur inside the bay itself, such as Anadara bivalvis, Nuculana electa, Pecten tehuelchus, Dorsanum moniliferum, Olivella verraux, Persephona punctata etc.

Five different station groups were recognized in the channel and in the bay region. The first of these (St. 1, 3. 4, 7, 8) has a viscous ooze smelling sulphydric acid, low salinity and oxygen tenor, besides high Littoridina australis var. nana density. The second (St. $2,5,10,13,16,18,19$ and 33 ) is the region comprising the Santos Channel itself, where we noticed a numerous and frequent occurrence of Audouinia tentaculata and Poecilochaetus australis. The third (St. 22, 24, 25 and 32) shows a sand bottom with dead shell, gravel, having ophiuran species. The fourth area (St. 28 to 31 and 40) is characterized for a muddy sand, for the occurrence of Ninoë sp. and Prionospio pinnata. The fifth (St. 9, 12 and 39) for the polychaets Loandalia americana and Owenia fusiformis.

Another area is the one of sandy beaches band whose faunistic zonation is very similar to the one observed by RoDRIGUES (1959) on the sandy beaches of Margarita Island (Venezuela). The seventh area is the mangrove region about which LUEDERWALDT (1919) published an important paper.

A comparison between the efficiency of the different benthic gears showed once more the need of employing different types of those devices in order to obtain a perfect inventory of the benthic species association of a given region.

\section{AGRADECIMENTOS}

Aos especialistas que determinaram os diversos grupos; à Dra. Marta Vannucci e ao Dr. Edmundo Nonato, pelas valiosas sugestões e críticas; aos Srs. Clarimundo de Jesus, Manoel Marcelino e Wilson Ribas, pelo auxílio nos trabalhos de campo; às Srtas. Leonor Fischmann e Leko Kanno pelo auxílio na triagem e contagem dos animais, nossos sinceros agradecimentos.

\section{B I B L I O G R A F I A}

AB'SÁBER, A.

1965. A serra do mar e o litoral de Santos. Anais Acad. bras. Cienc., vol. 37, supl. p. 395-397.

AlleE, W. C. et al.

1963. Principles of animal ecology. Philadelphia, Saunders, xii, $837 \mathrm{p}$.

AZEvedo, A., coord.

1965. A baixada santista: aspectos geográficos. São Paulo, Ed. Univ. S. Paulo, 4 vols.

BEANLAND, F. L.

1940. Sand and mud communities in the Dover estuary. J. mar. biol. Ass. U. K., vol. 24 , p. $589-611$.
BERNASCONI, I.

1956. Equinoideos y asteroideos de la colección del Instituto Oceanográfico de la Universidad de San Pablo. Segunda contribución. Bolm Inst. oceanogr., vol. 7, n. ${ }^{\circ} 1 / 2$, p. $119-148,4$ est.

BJöRNBERG, T. K. S.

1959. On Enteropneusta from Brazil. Bolm Inst. oceanogr., vol. 10, n. $^{\circ} 1,104$ p. 19 est. 6 map.

1963. On the marine free-living copepods off Brazil. Bolm Inst. oceanogr., vol. 13, n. ${ }^{\circ} 1$, p. 4-142, 51 figs.

Brasil. Ministério da Marinha. Diretoria de Hidrografia E NAVEgaÇão.

1957. V viagem do NE 'Almirante Saldanha'. Estudo da área entre o meridiano de Cabo Frio e o paralelo de $35^{\circ} \mathrm{S}$. DHNDG-06-V.

1958. VI viagem do NE 'Almirante Saldanha'. Rio - Rio Grande e Rio Grande - Santos. DHN-DG-06-VII.

Carvalho, J. de P.

1952. Nova espécie de Paraleptastacus Wilson 1952. Papéis Dep. Zool. S Paulo, Paulo, vol. 11, n. $0^{\circ}$, p. $37-40$.

Carvalho, J. de P. \& Chermont, E. M. L.

1952. Sôbre alguns Foraminifera da costa do Est. de São Paulo. Bolm Inst. oceanogr., vol. 8 , n. ${ }^{\circ} 1 / 2$, p. $77-100,1$ est.

Corrêa, D. D.

1948. A embriologia de Bugula flabellata (J.

V. Thomps.). Bolm Fac. Filos. Ciênc. Univ. S Paulo. Zool. n. 13 , p. 7-72, 8 est.

1949. Sôbre o gênero Zygantroplana. Bolm Fac. Filos. Ciênc. Univ. S Pauio, Zool. n. ${ }^{\circ} 14$, p. $173-218,5$ tab.

du Bois-Raymond Marcus, E.

1949. Phronis ovalis from Brazil. Bolm Fac. Filos. Ciênc. Univ. S Paulo, Zool. n. ${ }^{\circ}$ 14, p. $157-172,3$ est.

1950. A new loxosomatid from Brazil. Ibidem, n. ${ }^{\circ} 15$, p. 193-202, 2 est.

1957. Neue Entoprocten aus der Gegend von Santos. Zool. Anz., vol. 159, n. ${ }^{\circ} 3 / 4$, p. $68-75,7$ fig.

EMílsson, I.

1955. Pesquisas hidrográficas ao longo da costa da Ponta de Itaipú. In: Cunha, A. \& Neto, J. M. de A. - Lançamento dos esgotos sanitários de Santos e São Vicente, cap. 16.

1956. Relatório e resultados físico-químicos de três cruzeiros oceanográficos em 1956. Contrções Inst. oceanogr. Univ. $\mathrm{S}$ Paulo, sér. Ocean, fís., n. ${ }^{\circ} 1,70 \mathrm{p}$. fot. map.

1961. The shelf and costal waters off southern Brazil. Bolm Inst. oceanogr., vol. 11, n. ${ }^{\circ}$, p. 101-112.

ForNERIS, L.

1959. Phoronidea from Brazil. Bolm Inst. oceanogr., vol 10, n. $^{\circ} 2,50$ p. 22 est.

George, J. D.

1964. The life history of the cirratulid worm Cirriformia (= Audouinia) tentaculata Montagu on an intertidal mudflat. $\mathrm{J}$. mar. biol. Ass. U. K., vol. 44, p. 47-65, 9 fig.

GiLAT, E.

1963. Methods of study in marine benthonic ecology. Comm. int. Explor. sci. Mer Médit., Colloque Com. Benthos: méthodes quant. Et. benthos échel. dimension benthontes, p. $7-13,2$ fig. Marseille. 
Guimarães, M. S. \& Rosa, C. N.

1941. Sôbre a briozoofauna duma santola: Mithrax hispidus (Herbst). Bolm Fac. Filos. Ciênc. Univ. S Paulo, Zool. n. ${ }^{\circ}$ 22 , p. $305-312,1$ fig.

Holme, N. A.

1949. The fauna of sand and mud banks near the mouth of the Exe estuary. J. mar. biol. Ass. U. K., vol. 28, p. 189-237.

HUNT, O. D.

1926. The food of the bottom fauna of the Plymouth fishing grounds. J. mar. biol. Ass. U. K., vol. 13 , p. $560-599$.

Japão. Departamento Nacional de Pesca

1958. Relatório das pesquisas de campo de pesca efetuadas pelo 'Toko Maru'. Ja-

Joly, A. B. pão, Dep. Nac. Pesca, 228 p.

1957. Contribuição ao conhecimento da flora ficológica marinha da baía de Santos e arredores. Tese de Livre-Docência. São Paulo, Fac. Filos. Ciênc. Univ. S Paulo, 196 p. 19 est.

KLAPPENBACH, M. A.

1965. Lista preliminar de los Mytilidae brasileños con claves para su determinación y notas sobre su distribución. Anais Acad. bras. Cienc., vol 37, supl., p. 327-352.

KRETZ, J. \& BǘcherL, W.

1940. Contribuição ao estudo da anatomia e fisiologia do gênero Callinectes. Archos Zool. Est. S Paulo, vol. 1, p. 229-248.

LANG, K.

1956. Tanaidacea aus Brasilien. Kieler Meeresforsch., vol. 12, n. $^{\circ} 3$, p. 249-260, tab. $33-45$.

LANGe DE Morretes, F.

1949. Ensaio de catálogo dos moluscos do Brasil. Archos Mus. parana., vol. 7, p. 5-216.

LiMA, F. R. \& VAZzoler, A. E. A. de M.

1963. Sôbre o desenvolvimento das ostras e possibilidades da ostreicultura nos arredores de Santos. Bolm Inst. oceanogr., vol. 13 , n. ${ }^{\circ} 2$, p. $3-20,5$ figs. 5 tab.

LUEDERWALDT, $\mathrm{H}$.

1919. Os manguezais de Santos. Revta Mus. paul., vol. 11, p. 309-408, 1 fig.

Mangum, C. P.

1966. Two new species of Clymenella (Polychaeta, Maldanidae) from Brazil. Postilla, n. 104,10 p. 2 fig.

MANNING, R. B.

1966. Stomatop Crustacea. Campagne de la Calypso au large des cotes atlantiques de l'Amérique du Sud (1961-1962). I. Annls Inst. océanogr., Monaco, n. s., vol. 44 , p. $359-384,8$ fig.

Marcus, E.

1937. Briozoarios marinhos brasileiros (n. $\left.{ }^{\circ} 1\right)$.

1937. Briozoarios marinhos brasileiros (n $\left.{ }^{\circ} 1\right)$.
Bolm Fac. Filos. Ciênc. Univ. S Paulo, Zool. n. ${ }^{\circ}$ 1, 224 p. 29 est.

1938a. Idem $\left(\mathrm{n}^{\circ}\right.$ 2). Ibidem, Zool. $\mathrm{n}^{\circ} 2,157$
p. 29 est.

1938a. Idem $\left(\mathrm{n}^{\circ}\right.$ 2). Ibidem, Zool. $\mathrm{n}^{\circ}$ 2, 157
p. 29 est.

1938b. Briozoarios perfuradores de conchas. Archos Inst. biol., n. ${ }^{\circ}$ 9, p. 273-296.

1939. Briozoarios marinhos brasileiros (n. 3 ) Bolm Fac. Filos. Ciênc. Univ. S Paulo, Zool. n. ${ }^{\circ}$ 3, p. 111-299, 31 est.

1940. Os pantopoda brasileiros e os demais sul-americanos. Ibidem, Zool. n. ${ }^{\circ} 4, \mathrm{p}$. $3-144,17$ est.

1947. Turbelários marinhos do Brasil. Ibidem, Zool. n. ${ }^{\circ} 12$, p. $99-215,21$ tab.
1948. Turbellaria do Brasil. Ibidem, Zool n. ${ }^{\circ} 13$, p. 111-244, 2 tab.

1949. Turbellaria brasileiros. Ibidem, Zool. n. ${ }^{\circ} 14$, p. 7-156.

1950. Idem. Ibidem, Zool. n. ${ }^{\circ}$ 15, p. 5-192, 34 tab.

1952. Idem. Ibidem, Zool. n. ${ }^{\circ}$ 17, p. 5-188, 32 fig.

1954. Idem. Papéis Dep. Zool. S Paulo, vol. 11, n. 24, p. 519-589, 76 fig.

1955a. Opisthobranchia from Brazil. Bolm Fac. Filos. Ciênc. Univ. S Paulo, Zool. n. ${ }^{\circ} 20$, p. $89-200,30$ tab.

1955b. Sea-hares and side-gilles slugs from Brazil. Bolm Inst. oceanogr., vol. 6, n. ${ }^{\circ} 1 / 2$, p. $3-33,8$ est.

1957. On Opistobranchia from Brazil. J. Linn. Soc., Zool., vol. 43, n. ${ }^{\circ}$ 292, p. $390-486,247$ fig.

Marcus, E. \& Marcus, E.

1961. On Coryphellina rubrolineata O'Donoghue, 1929. Proc. malac. Soc., vol. 34, n. $^{\circ}$ 4, p. $224-227,10$ fig.

1962. A new Pycnogonum from Brazil. Bolm Inst. oceanogr., vol. 12 , n. ${ }^{\circ} 3$, p. $3-8$, 1 est.

1963a. On Brazilian supralittoral and brackish water snails. Ibidem, vol. 13, n. $^{\circ} 2$, p. 41-52.

1963b. Mesogastropoden von der Küste São Paulos. Abh. math.-naturw. Kl. Akad. Wiss. Mainz, n. ${ }^{\circ} 1,193$ p. 95 fig.

1964. Verzeichnis der euthyneuren Meersschnecken Brasiliens. Beitr. neotrop. Fauna, vol. 3, n. ${ }^{\circ}$ 3, p. $195-206$.

1965. On Brazilian supratidal and estuarine snails. Bolm Fac. Filos. Ciênc. Univ. S Paulo, Zool. n. ${ }^{\circ}$ 25, p. 19-82, 10 tab.

MCINTYRe, A. D.

1956. The use of trawl, grab and camera in estimating marine benthos. J. mar. biol. Ass. U. K., vol. 35, p. 419-429.

MuUs, B. J.

1964. A new quantitative sampler for the meiobenthos. Ophelia, vol. 2 , n. ${ }^{\circ} 2$, p. 209-216, 4 figs. 2 tab.

Neiva, G. S. \& Wise, S. P.

1963. The biology and fishery of the sea-bob shrimp of Santos Bay, Brazil. Proc. Gulf Caribb. Fish. Inst., 16th Annual Section, p. 131-139.

NoNATO, E. 1963.

Poecilochaetus australis sp. n. (Annelida, Polychaeta). Neotropica, vol. 9, n. ${ }^{\circ} 28$, p. 17-26, 11 fig.

REID, G. K.

1961. Ecology of inland waters and estuaries. New York, Reinhold, xvi +375 p.

REISH, D. J.

1963. A quantitative study of the benthic polychaetous annelids of Bahia de San Quentin, Baja California. Pacif. Nat., vol. 3 , n. 4 , p. $399-436$, 16 fig.

RIGHI, G.

1967a. Sôbre polyplacophora do litoral brasileiro. Papéis Dep. Zool. S Paulo, vol. 20, n. 9 , p. $85-98,47$ figs.

1967b. Sôbre alguns decapoda do Brasil (Crustacea Brachyura: Pinnotheridae e Parthenopidae). Papéis Dep. Zool. S Paulo, vol. 20 , n. ${ }^{\circ} 10$, p. $99-116,32$ p.

Rodrigues, G.

1959. The marine communities of Margarita Island, Venezuela. Bull. mar. Sci. Gulf Caribb., vol. 9 , n. $^{\circ}$ 3, p. $237-280$, fig. 26, 2 tab. 
RODRIGUES, S.

1965. Ocorrência de Callianasa major Say no litoral de S. Paulo. Ciênc. Cult. S Paulo, vol. 17, n. $^{\circ}$ 2, p. 226.

SANDERS, H. L.

1958. Benthic studies in Buzzards Bay. I. Animal-sediment relationships. Limnol. Oceanogr., vol. 3 , n. ${ }^{\circ} 3$, p. 245-258.

1960. Idem. III. Limnol. Oceanogr., vol. 5, n. ${ }^{\circ}$ 2, p. $138-153,3$ figs. 5 est.

1965. Time, latitude, and structure of marine benthic communities. Anais Acad. bras. Ciênc., vol. 37 , supl., p. $83-86$.

SANDERS, H. L. et al.

1963. A study of the intertidal fauna of Banrstable Harbor, Mass. Limnol. Oceanogr., vol. 7, n. $^{\circ} 1$, p. $63-79,1$ fig. 4 est.

SAWAyA, M. P.

1944. Raninoides schmitti, sp. n. (Crustacea, Brachyura). Bolm Fac. Filos. Ciênc Univ. S Paulo, Zool. n. ${ }^{\circ}$ 8, p. 137-142, 2 est.

Sawaya, P. \& Carvalho, J. de P.

1938. Ocorrência de Branchiostoma na baía de Santos. Bolm biol. Clube zool. Bras. n.s., vol. 3, n. $^{\circ} 2$, p. 43-46.

1950. On the Branchiostoma (Amphioxus) of the coast of São Paulo. Bolm Fac Filos. Ciênc. Univ. S Paulo, n. ${ }^{\circ} 15$, p. 235-237.

SAvilov, A. I.

1959. Biological aspect of the bottom fauna groupings of the North Okhotsk Sea. In: Nikitin, B. N. - Marine biology. Washington, Amer. Inst. biol. Sci., p. $67-136$

Silva, P. C. M. da

1952. Estudo preliminar da propagação do marulho de leste sôbre a plataforma continental do Est. de São Paulo e, em particular, da sua refracão e arrebentação, em Cananéia. Bolm Inst. oceanogr., vol. 3, n. $^{\circ} 1 / 2$, p. $35-38$.

Stickney, A. P. \& Stringer, L. D.

1957. A study of the invertebrate bottom fauna of Greenwich Bay, Rhode Island. Ecology, vol. 38, n. $^{\circ} 1$, p. $111-122,2$ tab.

Tommasi, L. R.

1957. Os equinodermas do litoral de São Paulo. I. Papéis Dep. Zool. S Paulo, vol. 13, n. $^{\circ} 2$, p. $19-44,30$ fig.
1958. Idem. II. Contrçôes Inst. oceanogr. Univ. S Paulo, sér. Ocean. biol., n. ${ }^{\circ}$, 27 p. 6 est.

1965a. Lista dos crinoides recentes do Brasil. Contrçōes Inst. oceanogr. Univ. S Paulo, sér. Ocean. biol., n. ${ }^{\circ} 9,33$ p. 30 fig.

1965b. Lista dos bagres marinhos e de água salobra do Brasil. Contrções Inst. oceanogr., Univ. S Paulo, sér. Ocean. biol., n. 10,11 p. 9 fig.

1966a. Lista dos equinoides recentes do Brasil. Contrções Inst. oceanogr., Univ. S Paulo, sér. Orean. biol., n. ${ }^{\circ} 11,50$ p. 73 fig. 9 est.

1966b. Distribuição geográfica de alguns equinodermas do Brasil. Revta bras. Biol., vol. 26, n. $^{\circ} 3$, p. 239-246.

VANNUCCI, M.

1949. Hydrozoa do Brasil. Bolm Fac. Filos. Ciênc. Univ. S Paulo, Zool. n. ${ }^{\circ}$ 14, p. 219-266, 3 tab.

1951. Distribuicão dos Hydrozoa até agora conhecidos nas costas do Brasil. Bolm Inst. paul. oceanogr., vol. 2 , n. ${ }^{\circ} 1$, p. 105-124.

1954. Hydrozoa e Scyphozoa existentes no Instituto Oceanográfico. II. Bolm Inst. oceanogr., vol. 5, n. $^{\circ} 1 / 2$, p. $95-150$, 6 est.

VANNucci Mendes, M.

1946. Hydroidea Tecaphora do Brasil. Archos Zool. Est. S Paulo, vol. 4, p. 535-598, 7 tab.

VANZOLINI, P. E., ed.

1964. História natural dos organismos aquáticos do Brasil: bibliografia comentada. São Paulo, Fundação de Amparo à Pesquisa, $452 \mathrm{p}$.

VIEIRA, B. B.

1947. Observações sôbre a maturacão de Xiphopenaeus kroeyeri no litoral de São Paulo. Bolm Mus. nac. Rio de J., n.s., Zool. n. ${ }^{\circ} 7,22$ p.

Yonge, C. M.

1928 Feeding mechanisms in the invertebrates. Biol. Rev., vol. 3, p. 21-76. 
TABELA II - Espécies coletadas nas dragagens dentro da baía de Santos

(Fig. 1)

\begin{tabular}{|c|c|c|c|c|}
\hline Estação & Local e data & $\begin{array}{l}\text { Prof. } \\
\text { m }\end{array}$ & Espécies & $\begin{array}{l}\text { N.o de } \\
\text { Exemplares }\end{array}$ \\
\hline 2 & $\begin{array}{l}\text { Ponta do Góis } \\
(1-7-60)\end{array}$ & 5 & $\begin{array}{l}\text { Glycera sp. } \\
\quad \text { (Poliqueta) }\end{array}$ & 4 \\
\hline 12 & $\begin{array}{l}24^{\circ} 45^{\prime} \mathrm{S} \\
46^{\circ} 19^{\prime} 24^{\prime \prime} \mathrm{W} \\
\text { (Próximo à I. das Palmas) } \\
\quad(20-7-60)\end{array}$ & 11. & $\begin{array}{l}\text { Hemipholis elongata } \\
\text { (Ophiuroidea) } \\
\text { Schizocardium brasiliensis } \\
\quad \text { (Enteropneusta) }\end{array}$ & 17 \\
\hline 13 & $\begin{array}{l}\text { Alinhamento I. das Palmas- } \\
\text { Ponta Itaipú } \\
24^{\circ} 20^{\prime} 30^{\prime \prime} \text { S } \\
46^{\circ} 20^{\prime} 30^{\prime \prime} \text { W } \\
\quad(20-7-60)\end{array}$ & 12 & $\begin{array}{l}\text { Tellina similis } \\
\quad \text { (Lamelibranquio) } \\
\text { Hemipholis elongata } \\
\quad \text { (Ophiuroidea) }\end{array}$ & 9 \\
\hline$\cdot 14$ & $\begin{array}{l}\text { Em frente à Ponta Itaipú } \\
(20-7-60)\end{array}$ & 12 & $\begin{array}{l}\text { Hemipholis elongata } \\
\quad \text { (Ophiuroidea) } \\
\text { Diamphiodia atra }\end{array}$ & $\begin{array}{l}96 \\
1\end{array}$ \\
\hline 25 & $\begin{array}{l}\text { Em frente à Praia do Góis } \\
(20-7-60)\end{array}$ & 5 & $\begin{array}{l}\text { Ophiothrix angulata } \\
\text { (Ophiuroidea) } \\
\text { Ophioderma januarii }\end{array}$ & 2 \\
\hline 26 & $\begin{array}{l}\text { Entre a I. das Palmas e Ponta } \\
\text { dos Limões } \\
(20-4-61)\end{array}$ & 8 & 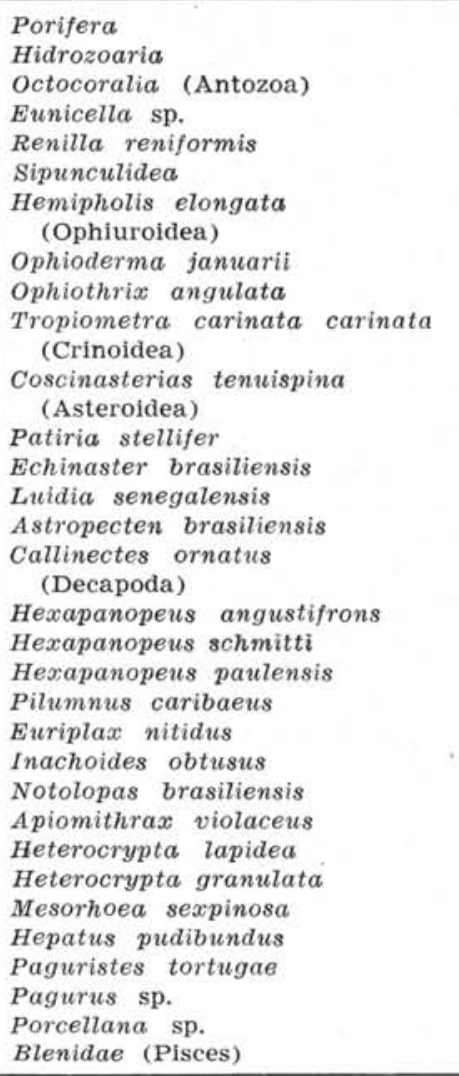 & $\begin{array}{r}1 \\
3 \\
10 \\
2 \\
5 \\
10 \\
4 \\
11 \\
3 \\
5 \\
\\
1 \\
16 \\
10 \\
4 \\
3 \\
1 \\
\\
5 \\
1 \\
15 \\
1 \\
1 \\
2 \\
9 \\
1 \\
8 \\
2 \\
1 \\
3 \\
2 \\
1 \\
1 \\
1 \\
\end{array}$ \\
\hline 125 & Em frente à praia do Gonzaga & 6 & $\begin{array}{l}\text { Luidia senegalensis } \\
\quad \text { (Asteroidea) } \\
\text { Tropiometra carinata } \\
\quad \text { (Crinoidea) }\end{array}$ & $\begin{array}{l}13 \\
2\end{array}$ \\
\hline 126 & $\begin{array}{l}23^{\circ} 58^{\prime} 20^{\prime \prime} \mathrm{S} \\
46^{\circ} 13^{\prime} 30^{\prime \prime} \mathrm{W} \\
\quad(22-2-66)\end{array}$ & 2 & $\begin{array}{l}\text { Ophioderma januarii } \\
\text { (Ophiuroidea) }\end{array}$ & 6 \\
\hline 127 & $\begin{array}{l}\text { Entre a I. Urubuquecaba e } \\
\text { I. Porchat } \\
(24-2-66)\end{array}$ & 12 & $\begin{array}{l}\text { Astropecten marginatus } \\
\quad \text { (Asteroidea) } \\
\text { Patiria stellifer } \\
\text { Luidia senegalensis } \\
\text { Ophioderma januarii } \\
\quad \text { (Ophiuroidea) }\end{array}$ & $\begin{array}{l}7 \\
1 \\
7 \\
8\end{array}$ \\
\hline
\end{tabular}


TABELA III - Espécies coletadas nas dragagens em frente à Ilha de Santo Amaro

(Figs. 1 e 2)

\begin{tabular}{|c|c|c|c|}
\hline $\begin{array}{l}\text { Esta- } \\
\text { cão }\end{array}$ & $\begin{array}{c}\text { Prof. } \\
\mathrm{m}\end{array}$ & Es pécies & $\begin{array}{c}\text { N.o de } \\
\text { Exemplares }\end{array}$ \\
\hline 3 & 15 & $\begin{array}{l}\text { Onuphis sp. (Poliqueta) } \\
\text { Eurytellina alternata (Lamelibranquio) } \\
\text { Anadara brasiliensis } \\
\text { Olivancillaria brasiliensis (Gastropoda) } \\
\text { Mellita 5-perforata (Echinoidea) } \\
\text { Astropecten marginatus (Asteroidea) }\end{array}$ & $\begin{array}{l}1 \\
1 \\
1 \\
2 \\
1 \\
3\end{array}$ \\
\hline 5 & 16 & $\begin{array}{l}\text { Telepsavus costarum (Poliqueta) } \\
\text { Amianthis purpurata (Lamelibranquio) } \\
\text { Tellina similis } \\
\text { Eurytellina alternata } \\
\text { Olivancillaria brasiliensis (Gastropoda) } \\
\text { Astropecten marginatus (Asteroidea) } \\
\text { Luidia senegalensis } \\
\text { Hemipholis elongata (Ophiuroidea) }\end{array}$ & $\begin{array}{l}3 \\
2 \\
4 \\
4 \\
2 \\
2 \\
1 \\
1\end{array}$ \\
\hline 6 & 18 & $\begin{array}{l}\text { Olivancillaria brasiliensis (Gastropoda) } \\
\text { Hyppolysmata oplophoroides (Decapoda) } \\
\text { Leander sp. }\end{array}$ & $\begin{array}{l}5 \\
4 \\
1\end{array}$ \\
\hline 6 & 16 & $\begin{array}{l}\text { Luidia senegalensis (Asteroidea) } \\
\text { Hemipholis elongata (Ophiuroidea) } \\
\text { Persephona punctata (Decapoda) } \\
\text { Discoporella umbellata (Briozoario) }\end{array}$ & $\begin{array}{l}3 \\
2 \\
1 \\
1\end{array}$ \\
\hline 8 & 18 & $\begin{array}{l}\text { Renilla reniformis (Anthozoario) } \\
\text { Nuculana electa (Lamelibranquio) } \\
\text { Tellina similis } \\
\text { Astropecten brasiliensis (Asteroidea) } \\
\text { Luidia senegalensis } \\
\text { Amphiodia limbata (Ophiuroidea) } \\
\text { Hemipholis elongata } \\
\text { Ophioderma januarii } \\
\text { Hepatus pudibundus (Decapoda) } \\
\text { Persephona punctata }\end{array}$ & $\begin{array}{r}2 \\
1 \\
1 \\
1 \\
1 \\
1 \\
15 \\
1 \\
1 \\
2\end{array}$ \\
\hline 9 & 23 & $\begin{array}{l}\text { Panthalis sp. (Poliqueto) } \\
\text { Maldanidae } \\
\text { Onuphis quadricuspis } \\
\text { Anadara brasiliensis (Lamelibranquio) } \\
\text { Anadara bivalvis } \\
\text { Pecten tehuelchus } \\
\text { Pecten sp. } \\
\text { Dorsanum moniniferum (Gastropoda) } \\
\text { Olivancillaria brasiliensis } \\
\text { Astropecten marginatus (Asteroidea) } \\
\text { Luidia senegalensis } \\
\text { Hemipholis elongata (Ophiuroidea) } \\
\text { Amphiodia limbata } \\
\text { Amphiuridae } \\
\text { Isopoda }\end{array}$ & $\begin{array}{r}6 \\
1 \\
1 \\
1 \\
1 \\
1 \\
1 \\
2 \\
1 \\
1 \\
1 \\
60 \\
2 \\
1 \\
1\end{array}$ \\
\hline
\end{tabular}


TABELA IV - Espécies coletadas nas estações fixas de hiđrografia e plâncton a) Pegador Van-Veen de 0,2 $m 2$

\begin{tabular}{|c|c|c|c|c|}
\hline $\begin{array}{l}\text { Esta- } \\
\text { ção }\end{array}$ & $\begin{array}{c}\text { Posição, Salinidade } \\
\text { e } \mathrm{T}^{\circ} \mathrm{C}\end{array}$ & $\begin{array}{l}\text { Prof. } \\
\text { m }\end{array}$ & ES PECIES & $\begin{array}{c}\text { N.o de Exempl. } \\
\text { p/m2 }\end{array}$ \\
\hline I & $\begin{array}{l}24^{\circ} 05^{\prime} \mathrm{S}-46^{\circ} 14^{\prime} \mathrm{W} \\
33,170^{\circ} \% \text { - superf. } \\
35,136^{\circ} \%-25 \mathrm{~m} \text { prof. } \\
22,40^{\circ} \mathrm{C}-\text { superf. } \\
21,31^{\circ} \mathrm{C}-25 \mathrm{~m} \text { prof. }\end{array}$ & 28 & $\begin{array}{l}\text { Discoporella umbellata } \\
\text { Goniada brunea } \\
\text { Magelona sp. } \\
\text { Audouinia sp. } \\
\text { Ninöe sp. } \\
\text { Laonice japonica } \\
\text { Olivella verraux } \\
\text { Amphipholis subtilis } \\
\text { Diamphiodia atra }\end{array}$ & $\begin{array}{r}565 \\
25 \\
10 \\
5 \\
5 \\
5 \\
5 \\
5 \\
5\end{array}$ \\
\hline II & $\begin{array}{l}24^{\circ} 14^{\prime} \mathrm{S}-46^{\circ} 08^{\prime} \mathrm{W} \\
34,330^{\circ} \%-\text { superf. } \\
35,220^{\circ} \%-35 \mathrm{~m} \\
22,40^{\circ} \mathrm{C}-\text { superf. } \\
21,12^{\circ} \mathrm{C}-35 \mathrm{~m}\end{array}$ & 35 & $\begin{array}{l}\text { Discoporella umbellata } \\
\text { Nephthys sp. } \\
\text { Onuphis quadricuspis } \\
\text { Lumbrinereis sp. } \\
\text { Scoloplos sp. } \\
\text { Thelepus setosus } \\
\text { Capitelideo } \\
\text { Spiophanes sp. } \\
\text { Clymenella sp. } \\
\text { Terebelideo } \\
\text { Ninöe brasiliensis } \\
\text { Prionospio sp. } \\
\text { Nemertineo } \\
\text { Stylarioides sp. } \\
\text { Owenia fusiformis } \\
\text { Notocirrus sp. } \\
\text { Pista sp. } \\
\text { Maldanideo } \\
\text { Afroditideo } \\
\text { Spio sp. } \\
\text { Glicerideo } \\
\text { Diamphiodia riisei } \\
\text { Lima sp. } \\
\text { Ampelisca sp. }\end{array}$ & $\begin{array}{r}2220 \\
80 \\
30 \\
20 \\
15 \\
15 \\
15 \\
10 \\
10 \\
10 \\
10 \\
10 \\
10 \\
5 \\
5 \\
5 \\
5 \\
5 \\
5 \\
5 \\
5 \\
5 \\
5 \\
5 \\
\end{array}$ \\
\hline III & $\begin{array}{l}24^{\circ} 16^{\prime} \mathrm{S}-46^{\circ} 00^{\prime} \mathrm{W} \\
35,120^{\circ} \% \text { superf. } \\
36,160^{\circ} \%_{00}-45 \mathrm{~m} \text { prof. } \\
21,70^{\circ} \mathrm{C}-\text { superf. } \\
21,29^{\circ} \mathrm{C}-45 \mathrm{~m} \text { prof. }\end{array}$ & 49 & $\begin{array}{l}\text { Discoporella umbellata } \\
\text { Stylarioides } \\
\text { Nemertineo } \\
\text { Arena gemini } \\
\text { Polinices hepaticus } \\
\text { Olivella sp. } \\
\text { Ampelisca brevisimulata } \\
\text { Liljeborgia sp. } \\
\text { Cumacea } \\
\text { Sipunculideo }\end{array}$ & $\begin{array}{r}1095 \\
15 \\
15 \\
5 \\
5 \\
5 \\
5 \\
5 \\
5 \\
5\end{array}$ \\
\hline IV & $\begin{array}{l}24^{\circ} 24^{\prime} \mathrm{S}-45^{\circ} 53^{\prime} \mathrm{W} \\
35,030^{\circ} \%_{00}-\text { superf. } \\
35,150^{\circ} \% \text { - } 55 \mathrm{~m} \text { prof. } \\
21,80^{\circ} \mathrm{C}-\text { superf. } \\
19,69^{\circ} \mathrm{C}-55 \mathrm{~m} \text { prof. }\end{array}$ & 60 & $\begin{array}{l}\text { Nephthys sp. } \\
\text { Ninöe sp. } \\
\text { Goniada sp. } \\
\text { Maldanideo } \\
\text { Loandalia sp. } \\
\text { Orbinea sp. } \\
\text { Lumbrinereis sp. } \\
\text { Diopatra sp. } \\
\text { Onuphis quadricuspis } \\
\text { Amphiuridae }\end{array}$ & $\begin{array}{r}25 \\
25 \\
10 \\
5 \\
5 \\
5 \\
5 \\
5 \\
5 \\
5 \\
\end{array}$ \\
\hline
\end{tabular}


TABELA IV - Espécies coletadas nas estações fixas de hidrografia e plâncton

b) Draga triangular

\begin{tabular}{|c|c|c|c|c|}
\hline Estaçāo & Posição & $\begin{array}{l}\text { Prof. } \\
\text { m }\end{array}$ & ESPECIES & $\begin{array}{l}\text { N.o de Exempl. } \\
\text { p/m2 }\end{array}$ \\
\hline III & $\begin{array}{l}24^{\circ} 16^{\prime} \mathrm{S} \\
46^{\circ} 00^{\prime} \mathrm{W}\end{array}$ & 49 & $\begin{array}{l}\text { Discoporella umbellata } \\
\text { Murex senegalensis } \\
\text { Oliva sayana } \\
\text { Calyptraeidae } \\
\text { Olivella jaspidea } \\
\text { Fusinus mucronatus } \\
\text { Conus sp. } \\
\text { Strombus goliatti } \\
\text { Solenolambrus sp. } \\
\text { Persephona punctata } \\
\text { Corophiidae }\end{array}$ & $\begin{array}{r}36 \\
5 \\
2 \\
2 \\
1 \\
1 \\
1 \\
1 \\
1 \\
1 \\
1\end{array}$ \\
\hline IV & $\begin{array}{l}24^{\circ} 24^{\prime} \mathrm{S} \\
45^{\circ} 53^{\prime} \mathrm{W}\end{array}$ & 60 & $\begin{array}{l}\text { Ninöe sp. } \\
\text { Asychis sp. } \\
\text { Nephthys sp. } \\
\text { Amotripane sp. } \\
\text { Discoporella umbellata } \\
\text { Onuphis quadricuspis } \\
\text { Pista sp. } \\
\text { Terebelidae } \\
\text { Lumbrinereis sp. } \\
\text { Glycera sp. } \\
\text { Clymene sp. } \\
\text { Nereis sp. } \\
\text { Marphysa sanguinea } \\
\text { Leanira sp. } \\
\text { Loandalia americana } \\
\text { Laonice japonica } \\
\text { Diopatra sp. } \\
\text { Glicinde sp. } \\
\text { Harmathoë lunulata } \\
\text { Poecilochaetus australis } \\
\text { Ceratocephala sp. } \\
\text { Capitelideo } \\
\text { Telepus setosus } \\
\text { Notocirrus sp. } \\
\text { Maldanideo } \\
\text { Pista sp. } \\
\text { Ampelisca brevisimulata } \\
\text { Ampelisca cuculata } \\
\text { Terebra protecta } \\
\text { Dentallium sp. } \\
\text { Murex senegalensis } \\
\text { Trillia acestra } \\
\text { Amphiura flexuosa } \\
\text { Amphiura complanata }\end{array}$ & $\begin{array}{r}17 \\
10 \\
6 \\
6 \\
5 \\
5 \\
5 \\
4 \\
4 \\
3 \\
2 \\
2 \\
2 \\
2 \\
1 \\
1 \\
1 \\
1 \\
1 \\
1 \\
1 \\
1 \\
1 \\
1 \\
1 \\
1 \\
2 \\
2 \\
2 \\
1 \\
1 \\
1 \\
1 \\
1\end{array}$ \\
\hline \multicolumn{5}{|c|}{ c) Otter Trawl } \\
\hline III & $\begin{array}{l}24^{\circ} 16^{\prime} \mathrm{S} \\
46^{\circ} 00^{\prime} \mathrm{W}\end{array}$ & 49 & \begin{tabular}{|l|} 
Prionotus alipionis \\
Sicyonia typica \\
Penaeus brasiliensis \\
Luidia clathrata \\
Hemisquilla brasiliensis \\
Portunus (Achelous) spinicarpus \\
Citharichthys spilopterus \\
Syacium papillosum \\
Etropus crossotus \\
\end{tabular} & $\begin{array}{r}22 \\
4 \\
3 \\
1 \\
1 \\
1 \\
1 \\
1 \\
1\end{array}$ \\
\hline IV & $\begin{array}{l}24^{\circ} 24^{\prime} \mathrm{S} \\
45^{\circ} 53^{\prime} \mathrm{W}\end{array}$ & 60 & $\begin{array}{l}\text { Portunus (Achelous) spinicarpus } \\
\text { Prionotus beanni } \\
\text { Penaeus brasiliensis } \\
\text { Hemisquilla brasiliensis } \\
\text { Squilla brasiliensis } \\
\text { Murex antillarum (?) } \\
\text { Tethyaster vestitus } \\
\text { Luidia scotti } \\
\text { Gymnachiurus zebrinus } \\
\text { Prionotus alipionis } \\
\text { Etropus crossotus } \\
\text { Xystreurys notatus } \\
\text { Citharichthys spilopterus } \\
\text { Syacium papillosum }\end{array}$ & $\begin{array}{r}268 \\
14 \\
6 \\
6 \\
2 \\
2 \\
2 \\
1 \\
2 \\
1 \\
4 \\
1 \\
1 \\
1\end{array}$ \\
\hline
\end{tabular}


TABELA V - Análise do sedimento das estações

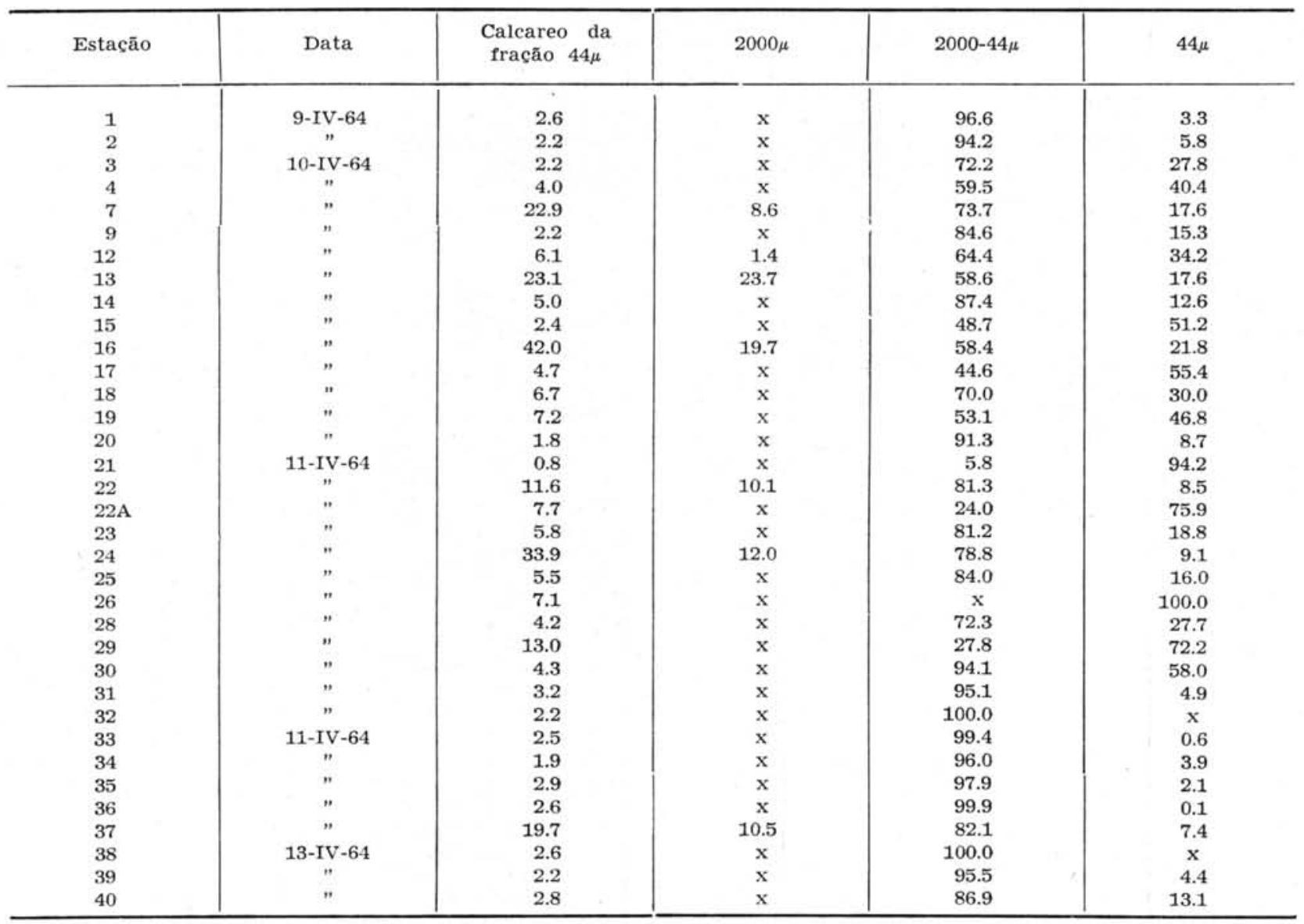

TABELA VI - Lista dos animais encontrados por Luederwaldt (1919), nos mangues de Santos

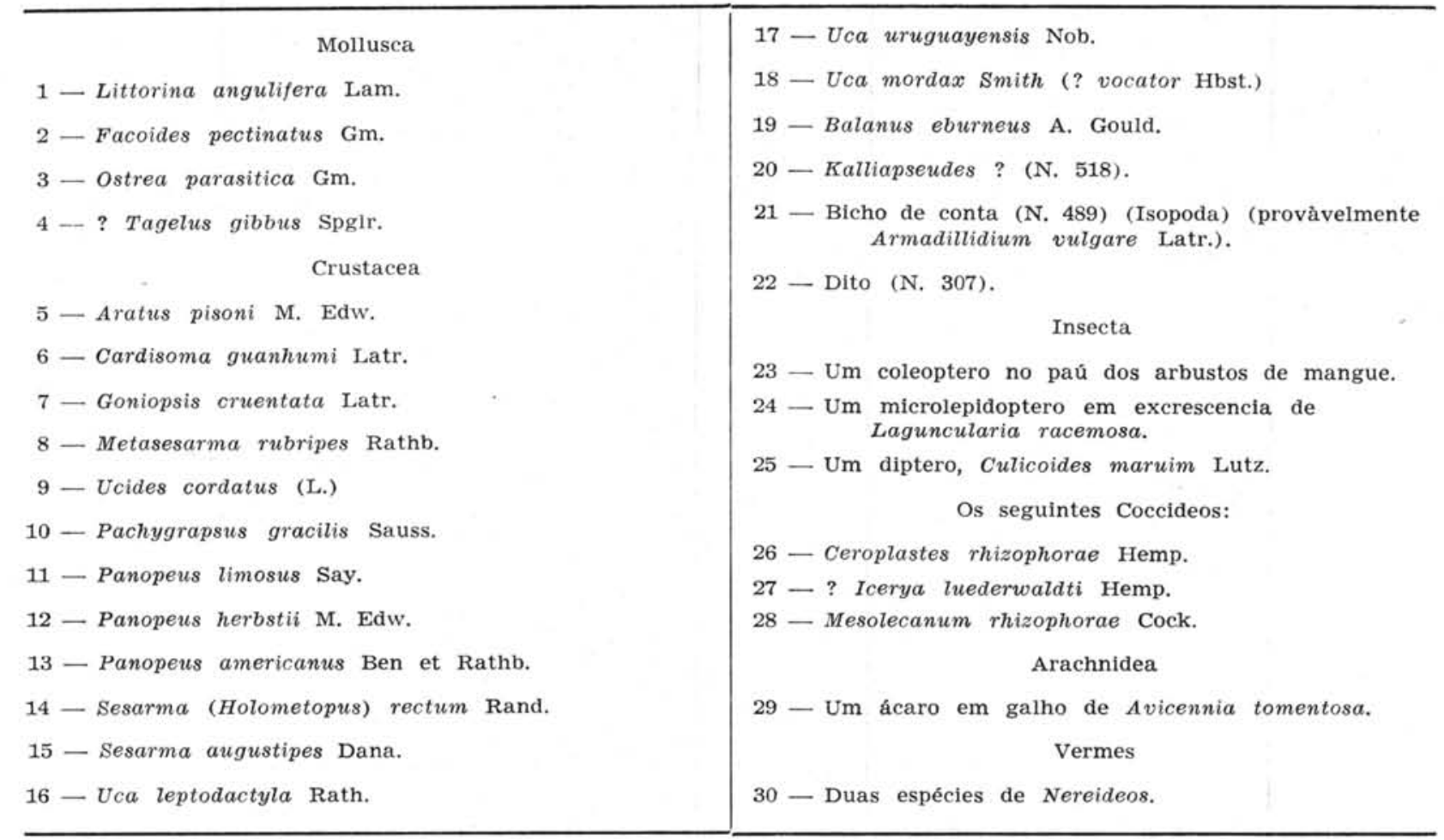




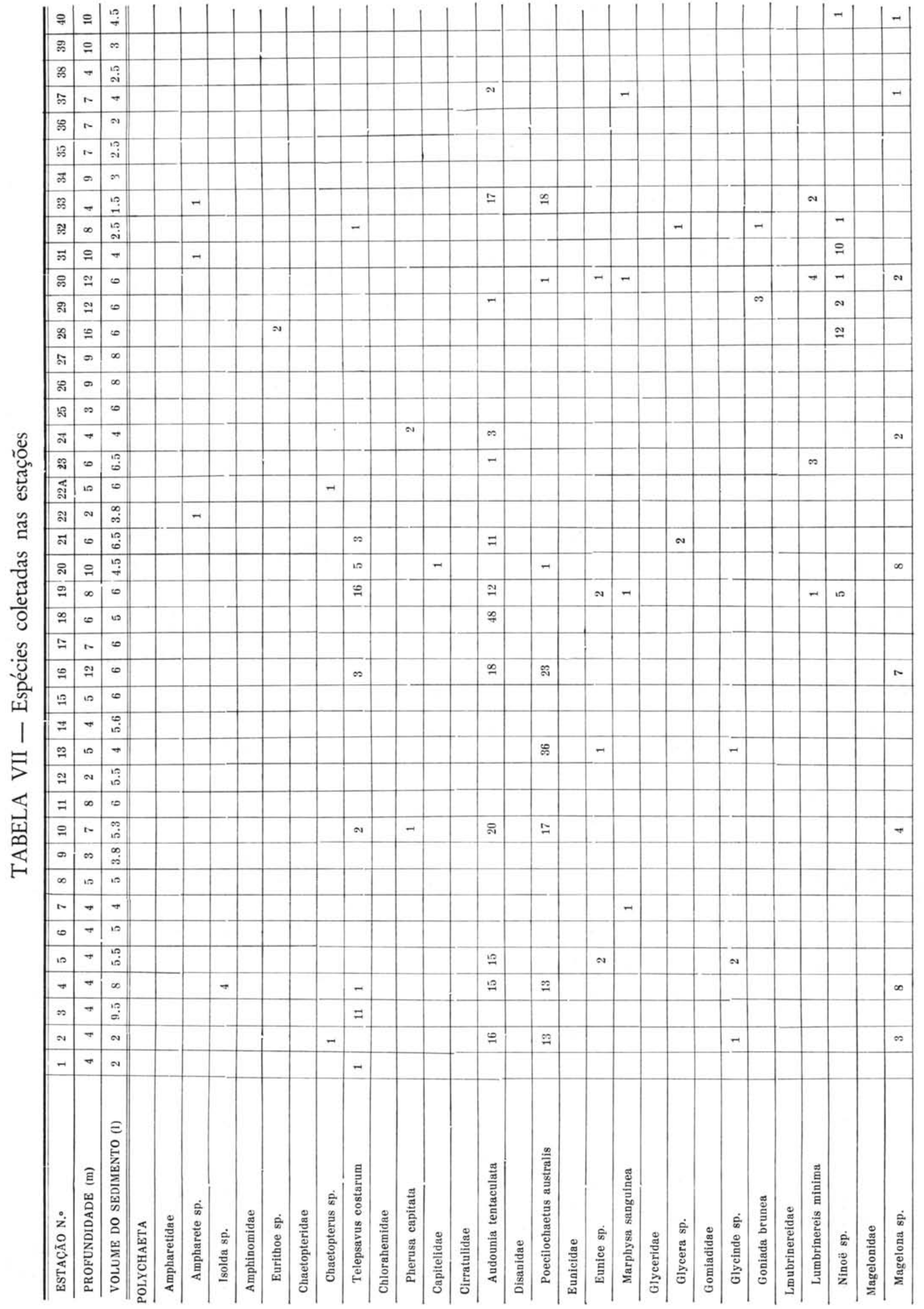




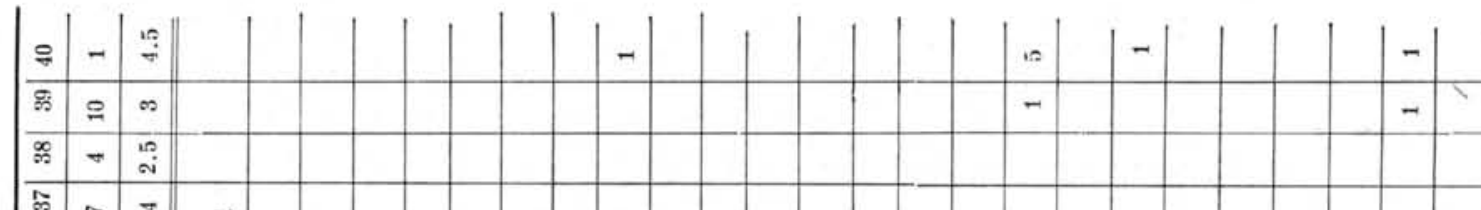

$$
\begin{aligned}
& \begin{array}{l|l|l||r|}
\hline \infty & n & - & - \\
\hline \infty & n & n & -
\end{array}
\end{aligned}
$$

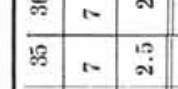

$$
\begin{aligned}
& \text { के } 0 \text { क }
\end{aligned}
$$

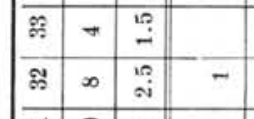

$$
\begin{aligned}
& \overline{5} \text { 운 }
\end{aligned}
$$

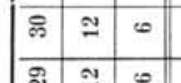

$$
\begin{aligned}
& \begin{array}{l|l|l|}
\hline \multirow{2}{*}{} & \multicolumn{1}{|c|}{} & 0 \\
\hline
\end{array}
\end{aligned}
$$

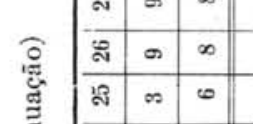

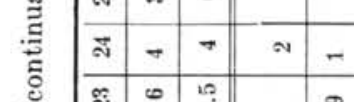

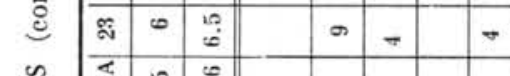

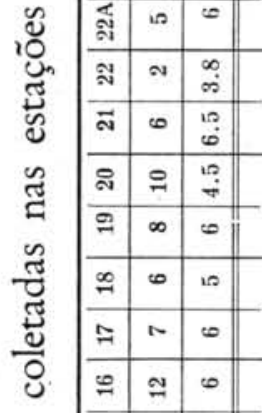

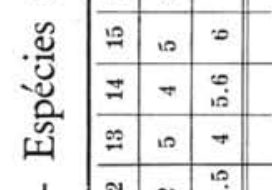

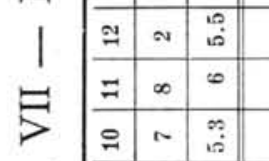

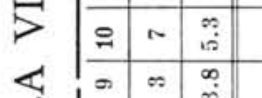

$$
\begin{aligned}
& \text { 空 }
\end{aligned}
$$

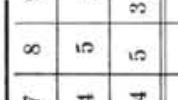

$$
\begin{aligned}
& +-\rightarrow
\end{aligned}
$$

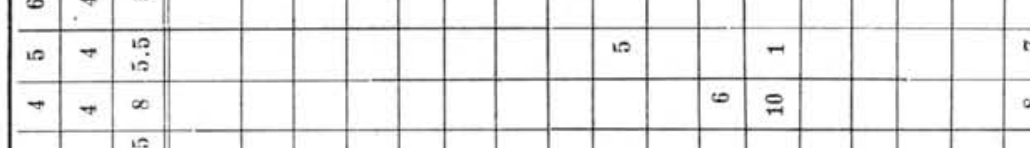

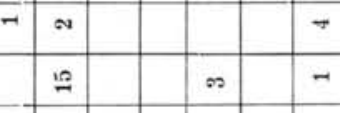

$$
\begin{aligned}
& \text { 구 }
\end{aligned}
$$

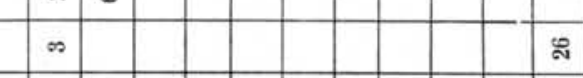

$$
\begin{aligned}
& \rightarrow-
\end{aligned}
$$

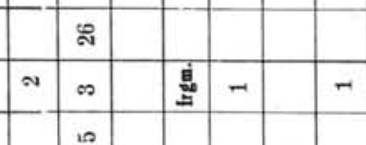

$$
\begin{aligned}
& \begin{array}{l|l|l|l|l|l|}
\hline & & & & & \\
\hline & & & & & \\
\hline & & & & & \infty \\
\hline
\end{array} \\
& \text {. } \\
& \begin{array}{lll|l|l|l|}
+ & & & & & - \\
\hline
\end{array}
\end{aligned}
$$

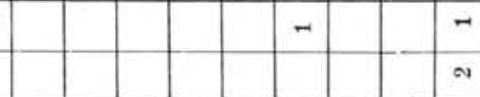

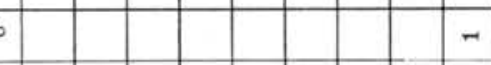

$$
\begin{aligned}
& \circ
\end{aligned}
$$

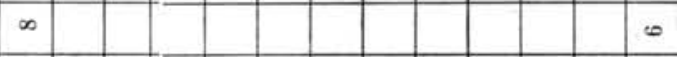

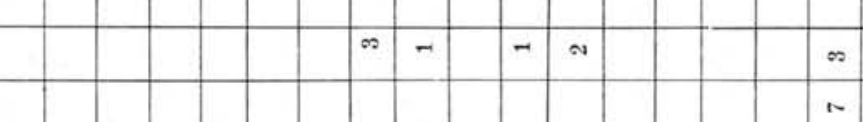

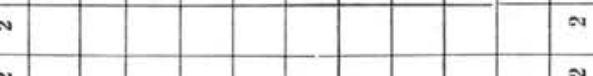

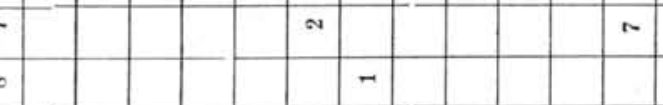

$$
\begin{aligned}
& \infty-\frac{1}{6}
\end{aligned}
$$

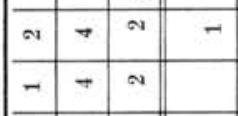

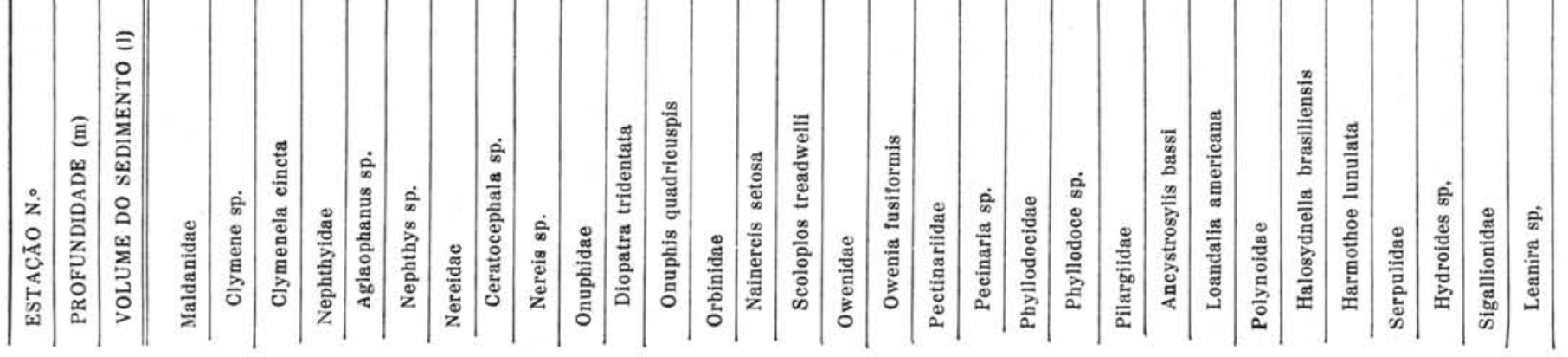




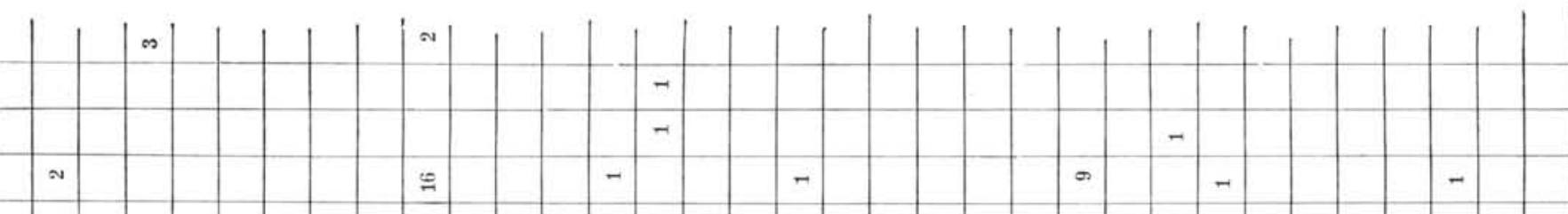

\begin{tabular}{ll|l|l|l|l|l|l|l}
\hline- & 1 & $\infty$ & & & & & \\
\hline & - & - & & & - & - \\
\hline & - & $\ddots$ & & & & - \\
\hline
\end{tabular}

s
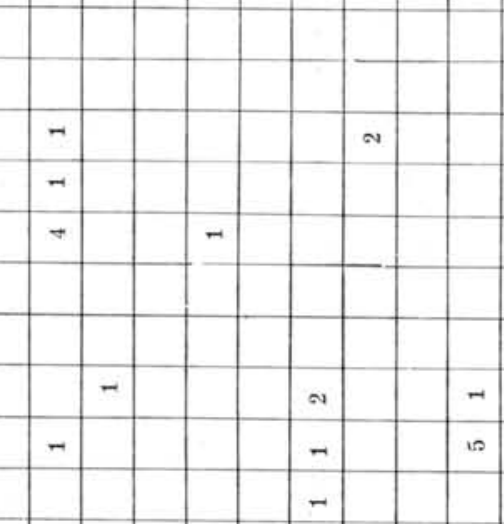

$$
\text { - }
$$

$-$

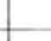

$$
\begin{array}{|l|l|l|l|l|l|l}
\hline & & & & & \\
\hline
\end{array}
$$




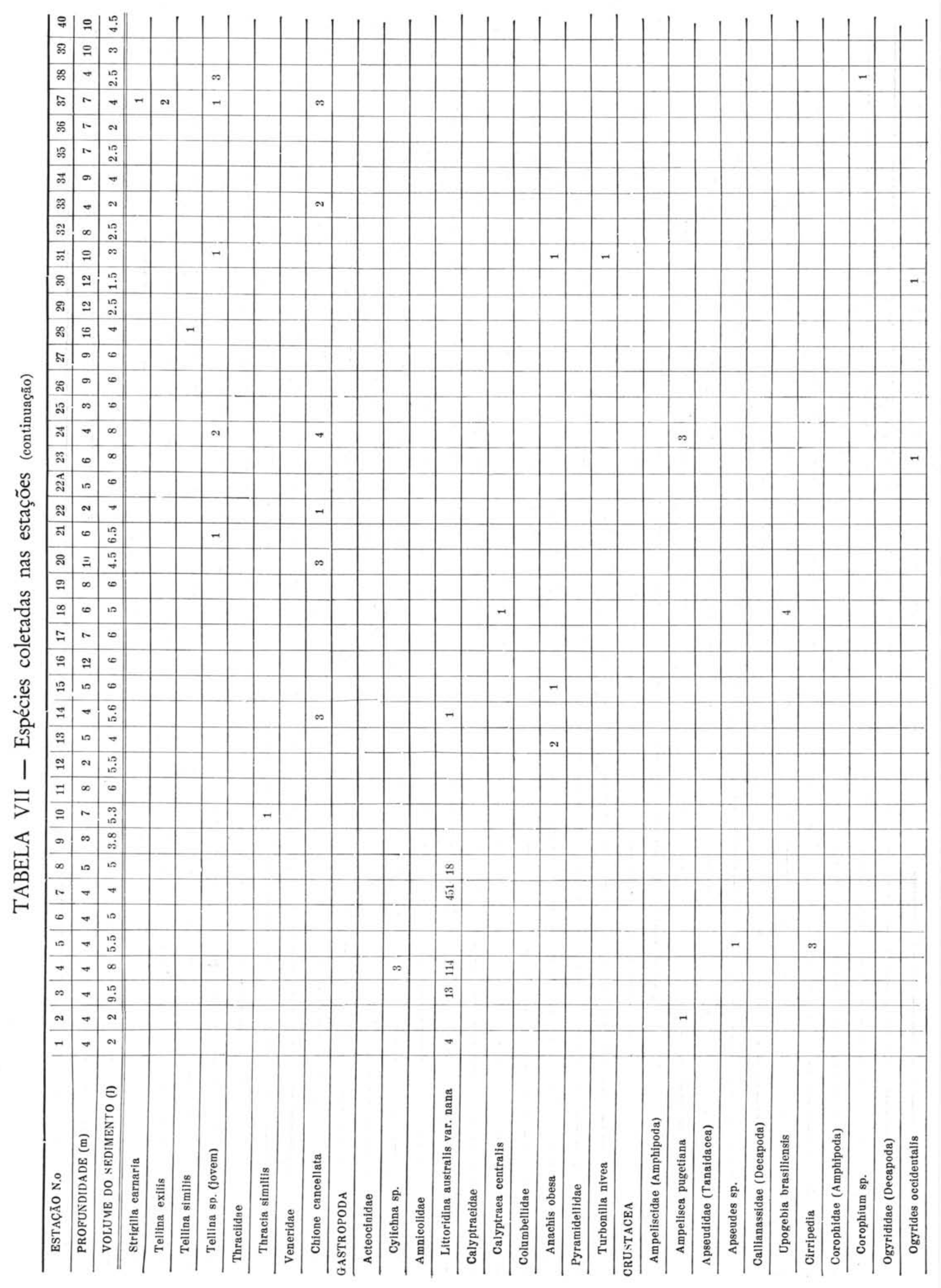




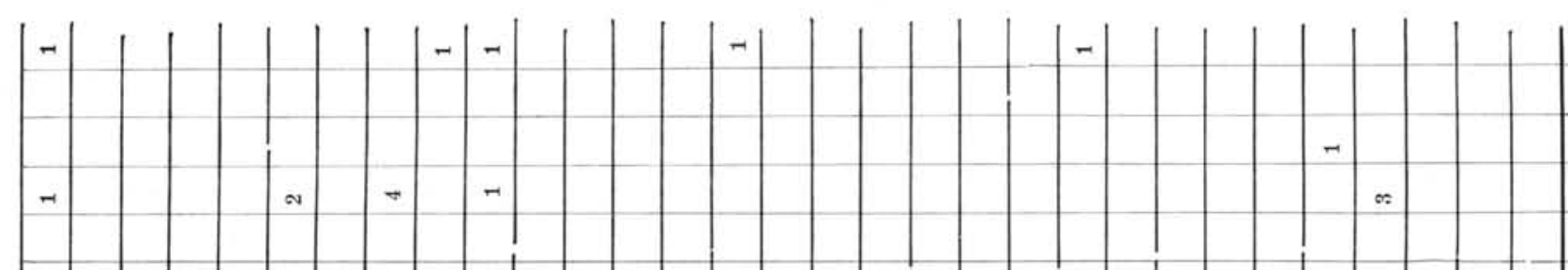

$$
-10
$$

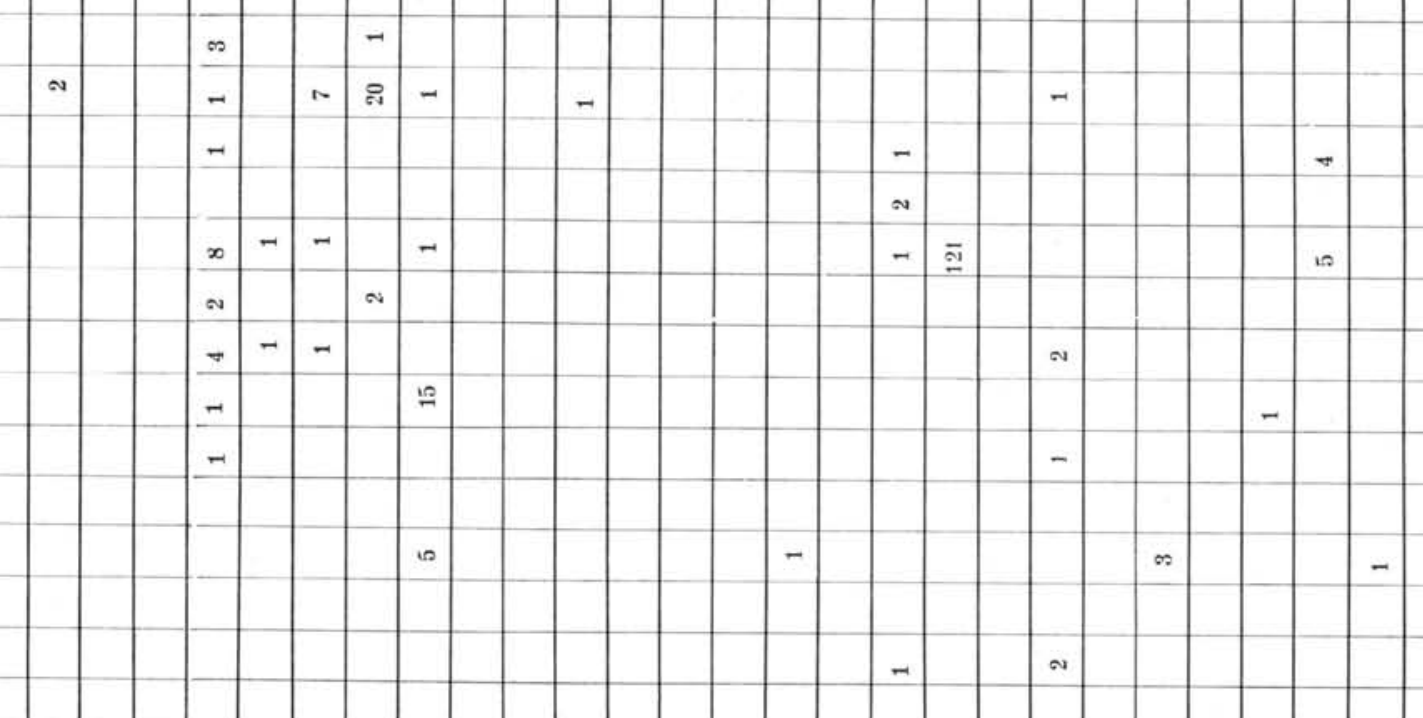$$
\begin{array}{|l|l|l|l|l|l|l|l|}
\hline \\
\hline
\end{array}
$$ 